\title{
Pharmacology of Vanilloid Transient Receptor Potential Cation Channels
}

\author{
Joris Vriens, Giovanni Appendino, and Bernd Nilius \\ Department of Molecular Cell Biology, Division of Physiology, Campus Gasthuisberg, Katholieke Universiteit Leuven, \\ Leuven, Belgium (J.V., B.N.); and Dipartimento di Scienze Chimiche, Alimentari, Farmaceutiche e Farmacologiche, \\ Università del Piemonte Orientale, Novara, Italy (G.A.)
}

Received February 16, 2009; accepted March 17, 2009

\begin{abstract}
Depending on their primary structure, the 28 mammalian transient receptor potential (TRP) cation channels identified so far can be sorted into 6 subfamilies: TRPC ("Canonical"), TRPV ("Vanilloid"), TRPM (“Melastatin"), TRPP ("Polycystin"), TRPML ("Mucolipin"), and TRPA ("Ankyrin"). The TRPV subfamily (vanilloid receptors) comprises channels critically involved in nociception and thermosensing (TRPV1, TRPV2, TRPV3, and TRPV4), whereas TRPV5 and TRPV6 are involved in renal $\mathrm{Ca}^{2+}$ absorption/reabsorption. Apart from TRPV1, the pharmacology
\end{abstract}

of these channels is still insufficiently known. Furthermore, only few small-molecule ligands for non-TRPV1 vanilloid receptors have been identified, and little is known of their endogenous ligands, resulting in a substantial "orphan" state for these channels. In this review, we summarize the pharmacological properties of members of the TRPV subfamily, highlighting the critical issues and challenges facing their "deorphanization" and clinical exploitation.
Transient receptor potential (TRP) cation channels are unique cellular sensors characterized by a promiscuous activation mechanism (Pedersen et al., 2005; Voets et al., 2005; Ramsey et al., 2006; Nilius et al., 2007). More than 50 members of the TRP family have been characterized in yeast, worms, insects, fish, and mammals (Vriens et al., 2004a;

This work was supported by the Belgian Federal Government; the Flemish Government; and the Onderzoeksraad Katholieke Universiteit Leuven [Grant GOA 2004/07, Fonds voor Wetenschappelijk Onderzoek G. 0136.00; Fonds voor Wetenschappelijk Onderzoek G. 0172.03, Interuniversity Poles of Attraction Program, Prime Ministers Office IUAP Nr.3P4/23, and Excellentiefinanciering EF/95/010]

Article, publication date, and citation information can be found at http://molpharm.aspetjournals.org.

doi:10.1124/mol.109.055624.
Nilius and Voets, 2005), making them one of the largest groups of ion channels. The 28 mammalian TRPs identified so far can be sorted out into 6 subfamilies: TRPC ("Canonical"), TRPM ("Melastatin"), TRPV ("Vanilloid"), TRPA ("Ankyrin"), TRPP ("Polycystin"), and TRPML ("Mucolipin") (Fig. 1). TRPs are classified essentially according to their primary amino acid sequence rather than selectivity or ligand affinity, because their properties are heterogenous and their regulation is complex. From a structural standpoint, TRP channels are membrane proteins with six putative transmembrane spans (TMs) and a cation-permeable pore region formed by a short hydrophobic stretch between TM5 and TM6. The structural differences within the TRP subfamilies have been recently reviewed (Owsianik et al., 2006), and

ABBREVIATIONS: TRP, transient receptor potential; TM, transmembrane domain; TRPV, transient receptor potential receptor vanilloid; AEA, $\mathrm{N}$-arachidonylethanolamine; NADA, N-arachidonoyldopamine; RTX, resiniferatoxin; TG, trigeminal; DRG, dorsal root ganglia; 2-APB, 2-aminoethoxydiphenyl borate; RR, ruthenium red; OLEA, N-oleoylethanolamine; HPETE, hydroperoxyeicosatetraenoic acid; HEK, human embryonic kidney; $\mathrm{IP}_{3}$, inositol triphosphate; CGRP, calcitonin gene-related peptide; PIP2, phosphatidylinositol biphosphate; PKA, protein kinase A; PKC, protein kinase C; 5HT, 5-hydroytryptamine; BCTC, $\mathrm{N}$-(4-tertiarybutylphenyl)-4-(3-cholorphyridin-2-yl)tetrahydropyrazine-1(2H)-carbox-amide; TBA, tetrabutylammonium; PI(3), phosphatidylinositol 3; PAR2, protease-activated receptor 2; QX-314, 2-((2,6-dimethylphenyl)amino)- $N, N, N$ triethyl-2-oxoethanaminium; DPTHF, 2,2-diphenyltetrahydrofuran; DPBA, diphenylboronic anhydride; PLA2, phospholipase A2; EET, epoxyeicosatrienoic acid; BAA, bisandrographolide A; PLC, phospholipase C; OAG, 1-oleoyl-acetyl-sn-glycerol; PTH, parathyroid hormone; DD161515, $N$-[2-(2-(N-methylpyrrolidinyl)ethyl]glycyl]-[N-[2,4-dichlorophenethyl]glycyl]- $N$-(2,4-dichlorophenethyl)glycinamide; U73122, 1-[6-((17 $\beta$-3-methoxyestra1,3,5(10)-trien-17-yl)amino)hexyl]-1H-pyrrole-2,5-dione; RN-1734, 1-alkoxycarbonylalkylidenetriphenylarsoranes. 
TRP proteins are essentially cation-permeable ion channels sensitive to a remarkable range of stimuli. Genetic approaches in worms, flies, and mice have demonstrated the involvement of TRPs in a variety of sensory processes that include thermosensation, osmosensation, olfaction, taste, mechanosensation, vision, and pain perception. Remarkably, mutations in different TRPs have also been linked to human diseases (Nilius et al., 2007).

Because TRPV1 is exquisitely sensitive to chemical gating, it seems reasonable to assume that small molecules, selective ligands, and endogenous ligands also exist for other TRPs, in particular for those from the vanilloid subclass (TRPVs). However, the search for these compounds has so far been largely elusive, even for the TRPs more closely related to TRPV1. In this review, we discuss the major reasons responsible for the orphan state of so many TRPs and review the current state of the pharmacological modulation of TRPV and the clinical potential of their manipulation.

\section{TRPV1}

The vanilloid receptor 1 , or TRPV1, the founding member of the mammalian TRPV channels, was identified in expression cloning experiments using capsaicin (compound 1) (Figs. 2-7) from hot pepper as a probe. Given the involvement of many TRPs in sensation and taste, it is not surprising that a compound of dietary origin was the first ligand to be discovered for this class of proteins. TRPV1 is a nonselective cation

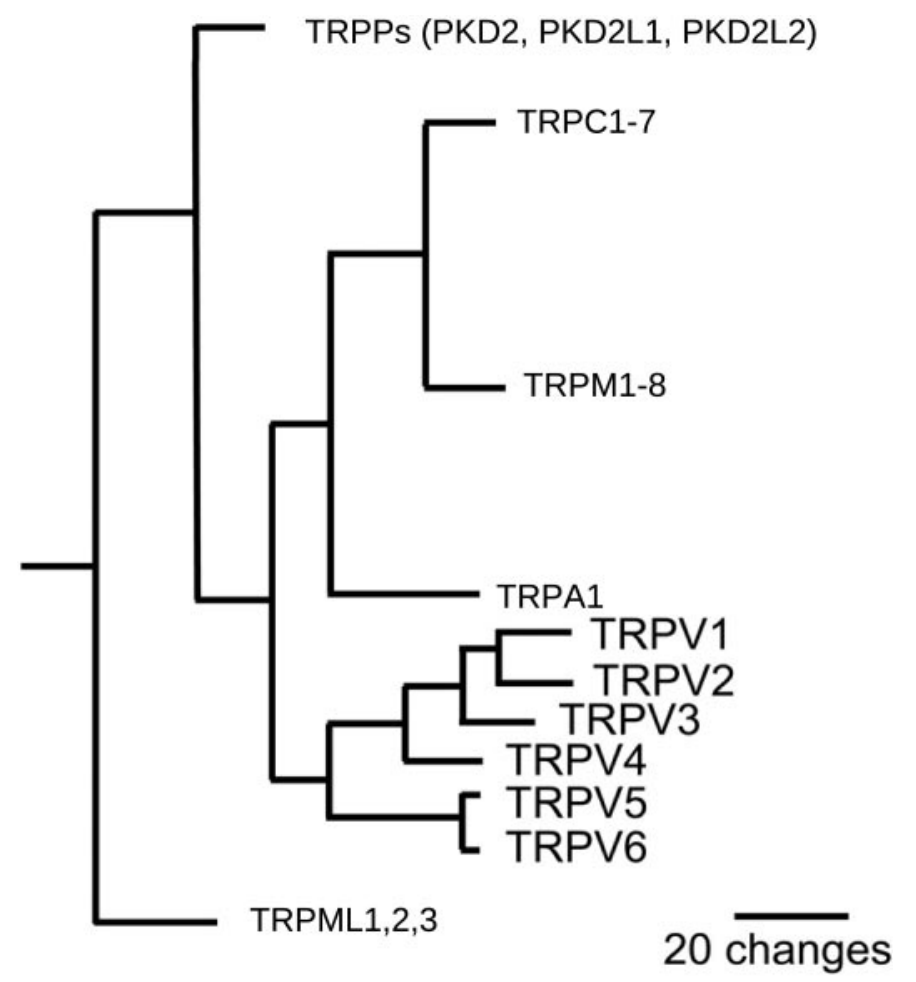

Fig. 1. Phylogenetic relations of the mammalian TRPV channels and their related other TRP subfamilies (polycystin TRPPs, canonical TRPCs, melastatin TRPMs, ankyrin TRPAs, and mucolipin TRPMLs). This consensus tree was obtained as described in detail in Yu and Catterall (2004) from an analysis of the pore regions. The scale bar corresponds to the number of changes in amino acids needed to explain the differences in the protein sequences. Note the distance between the highly $\mathrm{Ca}^{2+}$-permeable TRPV5, TRPV6, and the thermoTRPs, TRPV1 to -4. (For more details, see also Yu and Catterall, 2004; Montell, 2005; Nilius et al., 2007; and Vennekens et al., 2008.) channel with a preference for calcium and is activated by noxious stimuli, heat, protons, $\mathrm{pH}<5.9$, and various, mostly obnoxious, natural products (Tominaga et al., 1998). TRPV1 is predominantly expressed in sensory neurons (Caterina et al., 1997) and is believed to play a crucial role in temperature sensing and nociception (Caterina et al., 2000), qualifying therefore as a molecular target for pain treatment. Thanks to the availability of a wealth of TRPV1 ligands, this ion channel is also the best-characterized member of the TRPV subfamily in terms of expression pattern, properties, and clinical translation of its manipulation (Vennekens et al., 2008).

\section{TRPV1 Agonists}

A distinction should be made between direct activators of TRPV1 and sensitizers. Strictly speaking, capsaicin and its biological analogs isolated from plants and animals are essentially sensitizers, because they act by lowering the thermal "physiological" activation threshold of TRPV1. Nevertheless, because these compound bind directly to TRPV1, they are conveniently considered as direct activators, in contrast to compounds that do not bind TRPV1 and affect its functioning indirectly, which are referred to as sensitizers. Because of the large body of literature on TRPV1 ligands, only the most important chemotypes and the most recent additions are discussed here (Appendino et al., 2008), covering in a more exhaustive way the issue of the topology of the vanilloid binding site.

Endogenous Agonists. Good evidence has been presented on the existence of endogenous vanilloid agonists, a class of compounds referred to as endovanilloids, and on their capability to modulate the sensitivity of TRPV1 channels to thermal stimuli (Van Der Stelt and Di Marzo, 2004). Various lipids from the fatty acid pool have also been identified as TRPV1 activators. These compounds can be divided into conjugates of biogenic amines [e.g., $N$-arachidonylethanolamine (AEA, anandamide, 2a), $N$-arachidonoyldopamine (NADA, 3a), $N$-oleoylethanolamine (OLEA, 2b), $N$-arachidonolylserine, and various $N$-acyltaurines and $N$-acylsalsolinols] (Appendino et al., 2008) and oxygenated eicosatetraenoic acids (Ahern, 2003; Wang et al., 2005) like the lipoxygenase products 5-, 12-, and 15-hydroperoxyeicosatetraenoic acids (5S-, 12S-, 15S-HPETE, 4a-6a) (Hwang et al., 2000), their reduced hydroxylic analogs (4b-6b), prostaglandins, and leukotriene $\mathrm{B}_{4}$ (Huang et al., 2002). In addition, adenosine, ATP, and polyamines (such as spermine, spermidine, and putrescine) activate TRPV1, as well as acidic conditions, $\mathrm{pH}<5.9$, like those observed during inflammation (Szallasi and Di Marzo, 2004; McNamara et al., 2005; Xu et al., 2005; Ahern et al., 2006; Alexander et al., 2006; Siemens et al., 2006).

Endovanilloids of the fatty acid conjugate-type resemble capsaicinoids for the presence of a polar head and a lipophilic moiety linked by an amide group, but the polar head is generally aliphatic [ethanolamine in AEA (2a) and OLEA (2b)] or if aromatic, as in NADA (3a) (Hwang et al., 2000), is not of the guaiacyl but of the catechol type (NADA, 3a). Within this class of compounds, the term vanilloid is therefore devoid of structural meaning and refers exclusively to their biological profile.

Endovanilloids are promiscuous agents. Thus, AEA (2a) and NADA (3a) bind not only TRPV1 but also cannabinoid receptors, whereas OLEA $(\mathbf{2 b})$ also bind peroxisome proliferator-activated receptors. Within the many synthetic ana- 
logs of endovanilloids, of special interest are the methylated forms of $N$-oleoyldopamine (3b), because reversal of activity from agonist to antagonist is observed upon $O$-methylation of the catechol system, with 3 -methyl- $N$-oleoyldopamine $(\mathbf{3 c})$ acting as an agonist and 4-methyl- $N$-oleoyldopamine (3d) as an antagonist (Almási et al., 2008).<smiles>[R]CCCC(=O)NCCO</smiles><smiles>[R3]CCC(=O)NCCc1ccc([R6])c([R])c1</smiles>

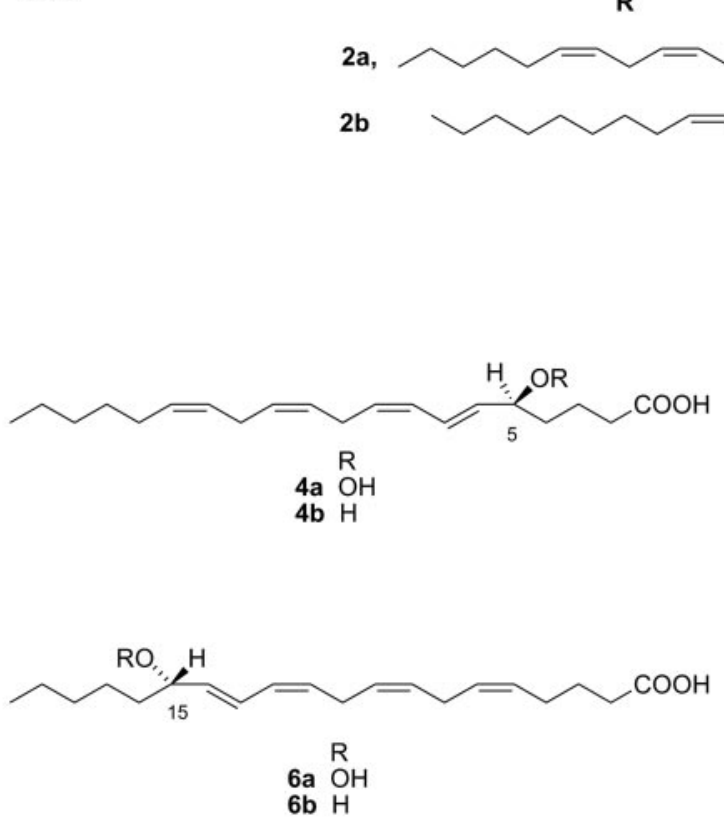

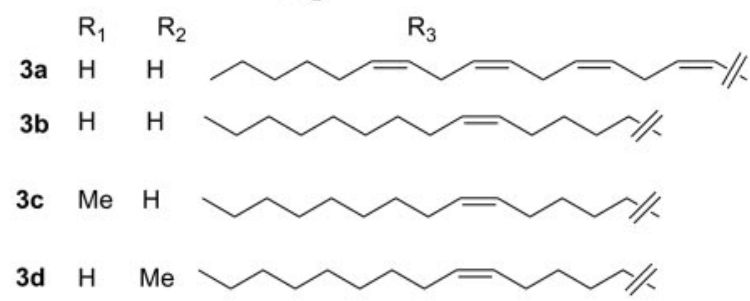

Fig. 2. Formulas of compounds $\mathbf{1}$ to $\mathbf{7 a , b}$.<smiles>O=C(/C=C/C=C/c1ccc2c(c1)OCO2)N1CCCCC1</smiles><smiles>[R]C(CC=CC)CCCCCC</smiles>

14<smiles>C=CCc1ccc(O)c(OC)c1</smiles><smiles>COCC(O)=C(O)OC</smiles>

$\Delta^{9}$<smiles>CCCCC(=O)NCc1ccc(O)c(OC)c1</smiles>

12b $\quad \mathrm{COCH}_{2} \mathrm{Ph} \quad \Delta^{9}$

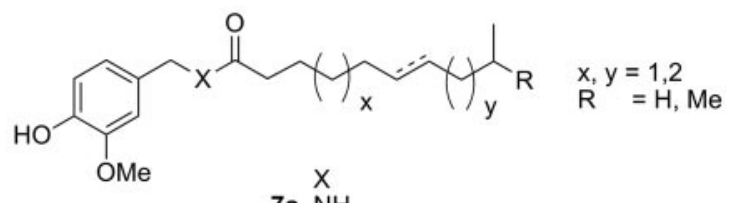

7a $\mathrm{NH}$

$7 \mathrm{~b} O$<smiles>C=CCSS(=O)CC=C</smiles>

16

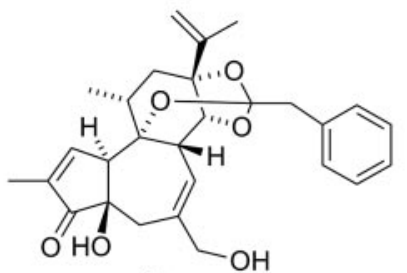

17<smiles>[X]C(NCc1ccc(C(C)(C)C([Y])(C)C)cc1)NCc1ccc(OCCN)c(OC)c1</smiles>

$18 \mathrm{~b} O$<smiles>COc1cc(CNC(=O)CCCC/C=C\C(C)C)ccc1O</smiles>

Fig. 3. Formulas of compounds $\mathbf{8}$ to $\mathbf{2 0}$ 
Polyamines are important endogenous regulators of TRPV1 channels that are capable of modulating inflammation and nociception. Extracellular spermine, spermidine, and putrescine directly activate TRPV1 in a charge-dependent manner, both in heterologous expression systems and in sensory neurons. The threshold for activation by spermine is rather high $(\sim 500 \mu \mathrm{M}$ at room temperature), but spermine can enhance capsaicinevoked currents with an $\mathrm{EC}_{50}$ value of approximately $5 \mu \mathrm{M}$. Experiments with TRPV1 mutants have identified extracellular acidic residues critical for polyamine regulation. Thus, neutralization of Asp646 abolished direct activation by spermine, whereas neutralization of this acidic residue or Glu648 inhib- ited spermine-induced sensitization. These data show that polyamines, by virtue of their cationic charge, can regulate the activity of TRPV1 at physiological concentrations (Ahern et al., 2006).

Exogenous Agonists of Natural, Semisynthetic, and Synthetic Origin. TRPV1 can be activated by a heterogenous array of natural products that includes both dietary compounds [capsaicinoids (7a) and capsinoids (7b), piperine (8), eugenol (9), and gingerol (10)], plant toxins [resiniferatoxin (RTX, 11a)], and animal toxins (Vriens et al., 2008). Capsaicinoids and capsinoids occur in plants from the genus Capsicum and are typical of hot (chili) and nonpungent (bell)

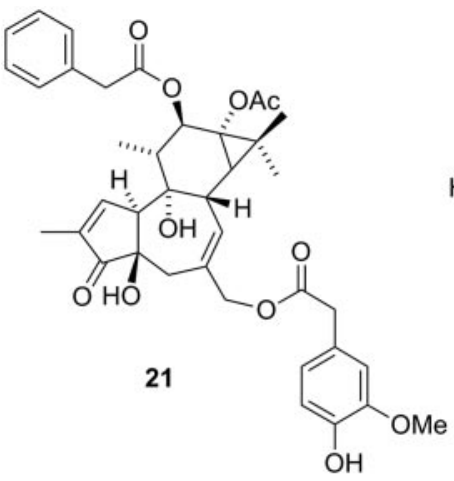<smiles>Oc1ccc2c(c1O)CCCN(C(=S)NCCc1ccc(Cl)cc1)C2</smiles><smiles>C=C(C)C(=O)O[C@H]1C(C)=C2[C@@H]3OC(=O)[C@@](C)(O)[C@@]3(O)[C@@H](OC(=O)CCC)C[C@]2(C)[C@H]1OC(C)=O</smiles><smiles>COC(=O)[C@@H]1[C@@H](O)CCC2CN3CCc4c([nH]c5ccccc45)C3C[C@H]21</smiles><smiles>CCNCCc1c[nH]c2ccc(O)cc12</smiles>
23 $\mathrm{OH}$

25<smiles>[Z20]c1cc(CC(CNC(=S)NCc2ccc(NS(C)(=O)=O)c(F)c2)COC(=O)C(C)(C)C)ccc1C</smiles><smiles>CCCCC(C)(C)c1ccc(CNC(=S)NCc2ccc(NS(C)(=O)=O)c(F)c2)cc1</smiles><smiles>CC(C)(C)c1ccc(NC(=O)N2CCN(c3ncccc3Cl)CC2)cc1</smiles><smiles>O=C(Nc1ccc(C(F)(F)F)cc1)Nc1cccc2cnccc12</smiles><smiles>O=C(Nc1ccccc1Br)N[C@H]1CCN(c2ccc(C(F)(F)F)cn2)C1</smiles><smiles>Cc1cccc(NCCNC(=O)Nc2ccccc2Br)c1</smiles><smiles>CC(C)(C)c1ccc2c(c1)CC[C@H]2NC(=O)Nc1cccc2[nH]ncc12</smiles>

Fig. 4. Formulas of compounds 21 to $\mathbf{3 2}$.<smiles>COc1cccc(NC(=O)/C=C/c2ccc(Cl)cc2)c1</smiles><smiles>O=C(/C=C/c1ccc(C(F)(F)F)nc1N1CCCCC1)Nc1cccc2c1CC(O)CC2</smiles><smiles>Cc1nc2cc(NC(=O)c3ccc(-c4ccc(F)cc4)nc3C)ccc2s1</smiles><smiles>CC(C)c1ccc(NC(=O)c2csc(Cc3c(Cl)cccc3Cl)n2)cc1</smiles><smiles>FC(F)(F)c1ccc(-c2[nH]c(N3CCN(c4ncccc4C(F)(F)F)CC3)nc2-c2ccccc2)cc1</smiles><smiles>CC(C)Nc1nc2c(Oc3cc(-c4ccc(C(F)(F)F)cc4)ncn3)cccc2s1</smiles>

Fig. 5. Formulas of compounds 33 to $\mathbf{4 0 .}$ 
peppers, respectively. More than 12 pungent capsaicinoids have been characterized from hot peppers and three major nonpungent capsinoids from bell peppers (Appendino, 2007). Capsaicinoids and capsinoids are characterized by an oxygenated vanillyl aromatic moiety bound via an amide (capsaicinoids) or ester (capsinoids) linker to a lipophilic acyl group. The vanillyl and the carbonyl linker contain polar groups capable of forming hydrogen bonds essential for activity, whereas the lipophilic moiety interacts with a corresponding cleft of the vanilloid binding site of TRPV1. Replacement of the medium-sized branched fatty acid of capsaicin with longer fatty acids is detrimental for activity (Morita et al., 2006), but remarkably, the presence of unsat- urations restores and potentiates activity, as exemplified by oleoylvanillamine (12a, olvanil), a compound 10-fold more potent than capsaicin in TRPV1 activation assays (Appendino et al., 2002) (Table 1). A further increase of potency was obtained by the introduction of polar functions on the acyl moiety of olvanil, as discovered for phenylacetylrinvanil (12b), the most potent capsaicinoid reported to date $(\sim 500$ fold more potent than capsaicin) (Appendino et al., 2005b). Capsiates are at least 1 order of magnitude less potent TRPV1 activators than capsaicin, but their lack of pungency is nevertheless puzzling. Unlike capsaicin, capsiates are hydrolytically unstable, and it has been suggested that they act essentially as prodrugs of vanillic alcohol (Rosa et al., 2005).<smiles>[R][R]([14CH3])(CCCNCCCNCCCCNCCCN)[13CH2]O</smiles><smiles>CCCN(CCC)S(=O)(=O)c1ccc(C(=O)O)cc1</smiles>

44<smiles>C=C(C)[C@@H]1CCC(C)=C[C@H]1c1c(O)cc(CCCCC)cc1O</smiles>

45<smiles>CCCCCc1cc(O)c2c(c1)OC(C)(C)[C@H]1CCC(C)=C[C@H]21</smiles>

46<smiles>CCCCCc1cc(O)c2c(c1)OC(C)(C)c1ccc(C)cc1-2</smiles>

47<smiles>CN1CCCC1CCNCC(=O)N(CCc1ccc(Cl)cc1Cl)CC(=O)N(CCc1ccc(Cl)cc1Cl)CC(N)=O</smiles>

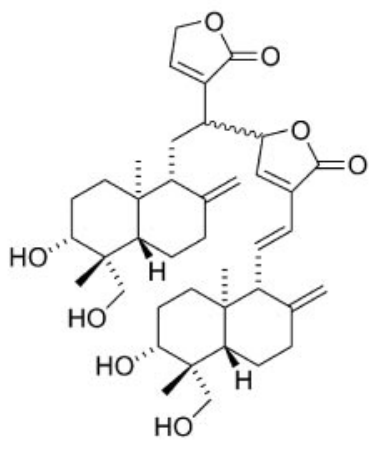

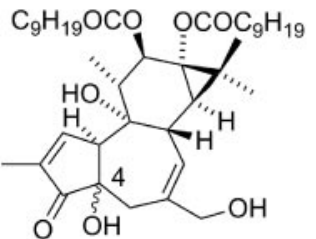<smiles>CC(C)C[C@H](NC(=O)c1cc2ccccc2s1)C(=O)N1CCN(C(=O)[C@H](CO)NS(=O)(=O)c2ccc(Cl)cc2Cl)CC1</smiles>

57<smiles>COc1ccc(CCCOC(Cn2ccnc2)c2ccc(OC)cc2)cc1</smiles><smiles>CC(=O)OCC/C(C)=C\CC/C(C)=C\C[C@@]1(C(C)C)CC[C@@H](C(C)C)O1</smiles>

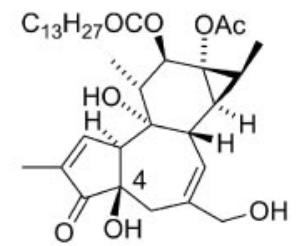

56 a $4 \alpha-\mathrm{OH}$

$56 \mathrm{~b} \quad 4 \beta-\mathrm{OH}$<smiles>Clc1ccc(COC(Cn2ccnc2)c2ccc(Cl)cc2Cl)cc1</smiles>

58

Fig. 7. Formulas of compounds 44 to $\mathbf{5 9}$. 
Piperine (8) belongs to a group of alkaloid typical of plants from the Piperaceae family, like black pepper (Piper nigrum L.), a most popular spice. Piperine shows putative anti-inflammatory activity, may promote digestive processes, and might increase the absorption of branched amino acids and several classes of small molecules of dietary and phytotherapy relevance (Srinivasan, 2007). The first evidence that piperine is a TRPV1 agonist was the demonstration of its ability to inhibit the binding sites of $\left[{ }^{3} \mathrm{H}\right] \mathrm{RTX}$ in the dorsal horn of pig spinal cord (Szallasi et al., 1991). In addition, piperine activates inward currents in TG neurons, an action that was found to be sensitive to capsazepine (Liu and Simon, 1996). In a more recent study, Gunthorpe and coworkers concluded that piperine is not only similar to capsaicin in its effects at human TRPV1 expressed in HEK293 cells but also exhibits a greater efficacy than capsaicin itself for both activation and desensitization of TRPV1 (McNamara et al., 2005). The reasons for the improved desensitization-to-excitation ratio of piperine compared with capsaicin are unclear. From a structural standpoint, there are three major differences between capsaicin and piperine, namely the replacement of the guaiacyl moiety with a methylendioxy group, a structural element associated with the inhibition of cytochrome P450 metabolism (Srinivasan, 2007), the presence of the aromatic moiety on the acyl and not the amine moiety, and the insertion of a four-carbon butadienyl linker between the amide and the aromatic moiety (Reen et al., 1996). An attractive hypothesis to explain the pharmacodynamic differences between capsaicin and piperine is that the latter might be a better inducer of dephosphorylative inactivation of TRPV1 (see below). Clearly, piperine is an attractive lead for the synthesis of improved TRPV1 agonists, but surprisingly, very little is known about its structure-activity relationships.

Eugenol (9), an allyl chain-substituted guaiacol, is a member of the allylbenzene class of phenylpropanoids. It is the major constituent of clove oil form Eugenia caryophyllata L. Electrophysiological studies have shown that eugenol is able to activate inward currents in hTRPV1-HEK293 cells and TG neurons. This effect was completely prevented by the TRPV1 antagonist capsazepine, demonstrating the involvement of TRPV1 (Yang et al., 2003).

Within nondietary naturally occurring vanilloids, a special position is held by resiniferatoxin (11a) from the dried latex of Euphorbia resinifera. The vanillyl group is critical for the activity of both capsaicin and RTX. This has led to the widespread use of the term "vanilloids" to refer to TRPV1 ligands. RTX is 3 to 4 orders of magnitude more potent than capsaicin both in terms of dose-response curve and effect on thermo- regulation and neurogenic inflammation (Szallasi and Blumberg, 1989) (Table 1). RTX is structurally more complex than capsaicin, and its structure-activity relationships are still largely unknown. The methylene linker between the side chain of the aromatic ring and the carbonyl is critical, as are the $\mathrm{C}-3$ carbonyl on ring $\mathrm{A}$ and the orthoester moiety in ring $\mathrm{C}$ of the diterpenoid core (Appendino et al., 2007). In addition, camphor (13), isolated from the wood of the camphor laurel tree (Cinnamomum camphora L.), can activate heterologously expressed TRPV1. Activation of rat TRPV1 by camphor is mediated by a distinct channel region from capsaicin because it is insensitive to the competitive TRPV1 antagonist capsazepine. Camphor activates TRPV1 less effectively than capsaicin (Table 1) but in a more rapid and complete way. However, camphor is a nonselective TRPV1 agonist because it also activates other TRP channels, including TRPV3 (Xu et al., 2005).

Spiders and jellyfish venoms are a major source of TRPV1 activators of animal origin. The presence of inhibitor cysteine knot peptides is the hallmark of venoms from Indian tarantulas, and three of these peptides, cogently named vanillotoxins, have been shown to activate TRPV1 $\left(\mathrm{EC}_{50}\right.$ values $\sim 10^{-8}$ to $\left.10^{-4} \mathrm{M}\right)$. TRPV1-mediated pain and inflammation are undoubtedly part of the mechanism by which animals avert predators (Siemens et al., 2006). From the marine front, the burning pain sensation caused by venom from the tentacles of certain cnidarians has been suggested to be mediated by the removal (or inhibition) of TRPV1 desensitization, although the clear mechanism is still uncertain (Cuypers et al., 2006). However, the active principle(s) of these venoms is still unknown (peptide versus bioactive small molecule), and their precise site of interaction remains to be elucidated (TRPV1 itself versus its signal-transduction pathway). The study of offensive animals has surely the potential to provide new probes to investigate TRPV1, but the field has not yet been systematically investigated. Finally, TRPV1 is also activated by the synthetic agent 2-aminoethoxydiphenyl borate (2-APB) $\left(\mathrm{EC}_{50}\right.$ value $\left.\sim 10^{-4} \mathrm{M}\right)$, a blocker of store-operated $\mathrm{Ca}^{2+}$ entry and $\mathrm{IP}_{3}$ receptors (Alexander et al., 2006).

Several synthetic drugs have been shown to interact with TRPV1. Thus, a surprising finding was the observation that the local anesthetic lidocaine (14) activates TRPV1, and, somewhat less efficiently, TRPA1, both in heterolog systems and in native rodent dorsal root ganglion sensory neurons. Lidocaine also induced a TRPV1-dependent release of calcitonin gene-related peptide (CGRP) from isolated skin and peripheral nerve. Activation of TRPV1 by lidocaine required segments of the putative vanilloid-binding domain within

TABLE 1

TRPV1 agonists

\begin{tabular}{clcclc}
\hline \multicolumn{1}{c}{ Group } & \multicolumn{1}{c}{ Compound } & Compound Number & $\mathrm{EC}_{50}$ & Species & Reference \\
\hline & & & & & \\
Endogenous agonists (fatty & Anandamide & $\mathbf{2 a}$ & $10^{-5}$ & Rat & Ahern (2003) \\
acids) & NADA & $\mathbf{3 a}$ & $10^{-8}-10^{-7}$ & Human and rat & Huang et al. (2002) \\
Exogenous agonists of natural, & Capsaicin & $\mathbf{5 a}$ & $10^{-5}$ & Human and rat & Hwang et al. (2000) \\
semisynthetic and synthetic & Piperine & $\mathbf{1}$ & $10^{-8}-10^{-6}$ & Rodent & Caterina et al. (1997) \\
origin & Eugenol & $\mathbf{8}$ & $10^{-5}-10^{-4}$ & Human & Liu and Simon (1996) \\
& Resiniferatoxin & $\mathbf{9}$ & $10^{-3}-10^{-2}$ & Human & Yang et al. (2003) \\
& Olvanil & $\mathbf{1 1 a}$ & $10^{-10}-10^{-8}$ & Rat & Szallasi and Blumberg (1989) \\
& Phar & $\mathbf{1 2 b}$ & $10^{-10}-10^{-9}$ & Human & Appendino et al. (2005b) \\
& Camphor & $\mathbf{1 3}$ & $10^{-11}-10^{-10}$ & Human & Appendino et al. (2005b) \\
& & $10^{-3}-10^{-2}$ & Rat & Xu et al. (2005) \\
\hline
\end{tabular}


and adjacent to TM3 and was decreased by PIP2 depletion, an effect mimicked by a point mutation at residue Arg701 in the proximal C-terminal TRP domain. TRPV1 and TRPA1 are novel players in lidocaine-induced nociceptor excitation and CGRP release and might also be involved in lidocaineinduced neurotoxicity (Leffler et al., 2008).

The modulation of TRPV1 signaling by covalent modification of a cysteine residue in the $\mathrm{N}$ terminus (Cys157) is complementary to the use of molecular probes to map the ligand-sensitive elements of TRPV channels. Thus, like TRPA1, TRPV1 is activated by pungent extracts from garlic and onion and their active component allicin (15) and alliin (16). These agents activate TRPV1 by covalent modification of one single cysteine residue (Cys157) via Michael addition. Consistent with this mechanism, treatment with dithiothreitol, a disulfur exchange agent, produced a near-complete reversal of activation by allicin. 2-Aminoethylmethane thiosulfonate hydrobromide sensitized the channel to capsaicin (Salazar et al., 2008), and it is therefore not surprising that mustard oil has been described as an activator of TRPV1 (in the millimolar range) (Ohta et al., 2007). Also a series of membrane-permeable oxidizing agents like diamide, chloramine-T, and copper (0) complexes can enhance the heat activation of TRPV1 by irreversible covalent modification of sulfhydryl groups. Extracellular application of the membraneimpermeable reducing agent glutathione mimicked the effects of dithiothreitol in potentiating the heat TRPV1 responses, suggesting that redox-active substances can directly modulate channel activity at sites of both extracellular and cytoplasmic location (Susankova et al., 2006).

The burning and irritation induced by capsaicin and related vanilloids represent a major shortcoming for the therapeutic use of these compounds. In addition, loss of the homovanillyl ester group of RTX would generate the tumorigenicity diterpenoid ROPA (17), an issue that so far has been largely unaddressed. The development of more potent, orally active vanilloids like olvanil (Alexander et al., 2006), SDZ-249482 (18a), and SDZ-249665 (18b) did not fully circumvent the discomfort of the side effects derived from irritation. In parallel to the identification of novel vanilloid agonists, research on the clinical translation of this class of compounds has also focused on innovative formulations for topical application as analgesics. In this context, the vanilloid analog DA-5018 (capsavanil, 19) and zucapsaicin (20) are currently being developed for this indication (Messeguer et al., 2006).

Ligand-Binding Site on TRPV1. In sharp contrast to other ligand-gated channels that produce fast synaptic transmission, vanilloids show slow activation kinetics, in part because their binding site is located in the intracellular portion of the receptor. Capsaicinoids, resiniferonoids, and endovanilloids are highly lipophilic compounds and must therefore cross the cell membrane to act on their intracellular binding site(s) on TRPV1. In fact, charged capsaicin analogs cannot cross the cell membrane and are only effective when applied to the intracellular surface (Jung et al., 1999). The dynamic of this process is largely unknown, but its relevance is highlighted by comparison between olvanyl and its saturate analog ( $N$-stearoylvanillamide, 12c) that is at least 5 orders of magnitude less potent as a TRPV1 ligand, presumably because of a very slow kinetics of penetration into the cell (Appendino et al., 2002).

Information on the ligand binding site of TRPV1 has re- cently surfaced. Molecular modeling studies on the xenovanilloid capsaicin (1) and the endovanilloid 12S-HPETE (5a) have suggested the sharing of specific amino acid residues in TRPV1 binding by these compounds (Hwang et al., 2000). A different approach was pursued by Julius and coworkers (Jordt and Julius, 2002), who capitalized on the observation that avian TRPV1 is heat- and proton-sensitive but capsaicin-insensitive to get clues as to the location of the capsaicinbinding site. Thus, comparison of the primary structure of the human and the avian isoforms of TRPV1 and mutational studies revealed a critical role for Tyr511 and Ser512, located at the transition between the second intracellular loop and TM3, confirming that the vanilloid binding site is located intracellularly (Jordt and Julius, 2002). By analyzing mammalian interspecies TRPV1 chimeras and site-directed TRPV1 mutants, a third critical residue in the putative TM4 segment (Met547 in rat, Leu547 in human and rabbit, Leu549 in guinea pig) was identified. These studies have benefited on the availability of isoform-specific ligands, like phorbol 12-phenylacetate 13-acetate 20-homovanillate (21), an agonist selective for rat TRPV1, and of vanilloid antagonists like capsazepine (22) (Chou et al., 2004; Gavva et al., 2005). Tyr550 in rat and human also seems to contribute to vanilloid binding (Gavva et al., 2005), whereas Arg114 and Glu761 in the $\mathrm{N}$ and $\mathrm{C}$ termini, respectively, are involved in the different ligand sensitivity of TRPV1 and TRPV2. The loss of proton activation in these mutants suggests that both residues may play a role in the general activation by agonists. The scattered distribution, in terms of primary structure, of the aminoacyl residues necessary for capsaicin binding suggests that in the tertiary and quaternary structure of the native channel, these critical residues are relatively close to each other. Possibly other unidentified regions required for capsaicin binding might also exist.

The current helix-packing models of the voltage-gated $\mathrm{K}^{+}$ channels, as derived from helical periodicity analysis and crystallographic approaches, show that the first, second, and third TM domains are located on the lipid-facing periphery of the tetrameric channel complex, whereas the fifth and sixth TM domains are located closer to the pore-forming channel core. Assuming similar helix-packing also for TRPV1, the lipophilic moiety of capsaicin may bind to the second and third TM domains on the channel-lipid interface, whereas the vanilloid moiety may interact with residues around Tyr511 in the cytosolic region, thus linking the two TM domains together with the cytosolic tail. The structural determinants involved in capsaicin binding are, overall, still poorly defined, but several molecular models for the vanilloid site have been proposed, which, upon refinement and validation, may facilitate the design of agonists with better therapeutic index than the current ligands.

Extracellular protons are believed to act primarily by increasing the probability of channel opening rather than by altering unitary conductance or interacting directly with the vanilloid-binding site (Baumann and Martenson, 2000). Acid solutions evoke ionic currents with an $\mathrm{EC}_{50} \sim \mathrm{pH} 5.4$ when applied to outside-out but not inside-out membrane patches excised from HEK293 cells expressing TRPV1 (Baumann and Martenson, 2000). This observation suggests that protons act on amino acid(s) located in the extracellular domain of TRPV1, presumably causing protonation of one or more critical carboxylates. Surprisingly, TRPV1 is also activated by 
gadolinium (III) ions $\left(\mathrm{EC}_{50}\right.$ value $\sim 72 \mu \mathrm{M}$ at $+40 \mathrm{mV}$ ), an effect that requires the pore residues Glu600 and Glu648, two protonation sites close to the selectivity filter. $\mathrm{Gd}^{3+}$ also potentiates TRPV1 activation by capsaicin, and the two effects (activation and potentiation) might be related to the neutralization of specific proton binding sites (Tousova et al., 2005).

Sensitizers. One important aspect of TRPV1 regulation that has received considerable attention concerns the mechanisms by which the inflammatory mediators in damaged tissues sensitize TRPV1 to its chemical and physical stimuli. Whereas capsaicin acts directly on TRPV1, others influence TRPV1 indirectly, via receptors of intrinsic tyrosine kinase pathways, G-protein-coupled receptors, or receptors coupled to the Janus tyrosine kinase/signal transducer and activator of transcription signaling pathway. Like other ion channels, TRPV1 can be phosphorylated by kinases including PKA (Bhave et al., 2002), protein kinase C (PKC; Bhave et al., 2003), $\mathrm{Ca}^{2+} / \mathrm{CaM}-$ dependent kinase II (Jung et al., 2004), or Src kinase (Jin et al., 2004). TRPV1 activity is also strongly modulated by phosphatidylinositol phosphates. Indeed, PIP2 seems to be associated constitutively with TRPV1 (Nilius et al., 2008).

PKA plays a pivotal role in the development of hyperalgesia and inflammation by inflammatory mediators. Ser116 and Thr370 in the amino terminus of TRPV1 are reportedly phosphorylated by PKA and are involved in desensitization (Mohapatra et al., 2003), whereas phosphorylation of Ser116 by PKA inhibits dephosphorylation of TRPV1 caused by capsaicin exposure.

PKC-dependent phosphorylation of TRPV1 occurs downstream from the activation of $\mathrm{G}_{\mathrm{q}}$-coupled receptors by several inflammatory mediators, including ATP, bradykinin, prostaglandins, and trypsin or tryptase (Tominaga et al., 2001; Sugiura et al., 2002; Moriyama et al., 2003). PKC-dependent phosphorylation of TRPV1 not only potentiates capsaicin- or proton-evoked responses but also reduces the temperature "threshold" for TRPV1 activation so that normally nonpainful temperatures in the range of normal body temperature become capable of activating TRPV1 and generate a sensation of pain. Direct phosphorylation of TRPV1 by PKC has been located at Ser502 and Ser800 (Bhave et al., 2003), but the precise isoform of PKC responsible for TRPV1 sensitization in sensory neurons has not yet been identified.

Also calcineurin inhibits desensitization of TRPV1, indicating that a phosphorylation/dephosphorylation process is important for TRPV1 activity. Indeed, $\mathrm{Ca}^{2+} / \mathrm{CaM}$-dependent kinase II reportedly controls TRPV1 activity upon phosphorylation of TRPV1 at Ser502 and Thr704 by regulating capsaicin binding (Jung et al., 2004). Phosphorylation of TRPV1 by three different kinases seems therefore to control channel activity, dynamically balancing phosphorylation and dephosphorylation.

Sensitization by PKC seems to involve increased exocytotic delivery of TRPV1 to the plasma membrane (Morenilla-Palao et al., 2004). Likewise, insulin and insulin-like growth factor-I increase translocation of TRPV1 to the plasma membrane via activation of receptor tyrosine kinases, which, in turn, leads to PI(3) kinase and PKC activation (Van Buren et al., 2005). Neurotrophic factors, such as nerve growth factor, glia-derived growth factor, and neurotropin 3, also increase the number of TRPV1 expressing neurons in sensory ganglia, elevate TRPV1, and increase the response to capsaicin in single DRG neurons. This "neurotrophic factor-induced gain of TRPV1 function" may relate to the pathophysiological significance of TRPV1, generating pain during tissue repair and growth (Anand et al., 2006).

Activation of TRPV1 is potentiated by stimulation of the metabotropic 5-hydroxytryptamine (5HT) receptors $5 \mathrm{HT}_{2 \mathrm{~A}} \mathrm{R}$ and $5 \mathrm{HT}_{7} .5 \mathrm{HT}$ is released in injured and inflamed tissues and causes hyperalgesia. This potentiation is due to $5 \mathrm{HT}$ receptor-mediated activation of PKA and PKC (Ohta et al., 2006). NGF potentiates TRPV1 activation via binding to its TrkA receptor. This effect is attenuated by wortmannin, a PI(3) kinase inhibitor. PI(3) kinase is directly bound to TRPV1 via its p85 binding, as shown elegantly by total internal reflection fluorescence. An increased plasma membrane insertion of functional TRPV1 is induced, leading to a potentiation of currents through these channels and ultimately causing thermal hyperalgesia by proalgesic agents as NGF (Stein et al., 2006). However, PI(3)K binding to TRPV1 does not seem to be promoted by NGF and does not result in TRPV1 tyrosine phosphorylation (as shown for Tyr199; Zhang and McNaughton, 2006).

Within eicosanoids, prostaglandin E2 and prostacyclin sensitize TRPV1 through $\mathrm{EP}_{\mathrm{I}}$ or IP receptors and PKC activation. Furthermore, a PKA-sensitive pathway for TRPV1 activation via EP4 and IP receptors (prostaglandin E2 and prostacyclin) has also been postulated (Moriyama et al., 2005).

TRPV1 is sensitized by activation of the protease-activated receptor 2 (PAR2) (Amadesi et al., 2004). PAR2 colocalizes with $\mathrm{PKC} \varepsilon$ and $\mathrm{PKA}$ and, upon stimulation, causes $\mathrm{PKC} \varepsilon$ and PKA-dependent activation of TRPV1 (Amadesi et al., 2006), ultimately triggering the thermal hyperalgesia that underlies inflammatory pain (Elitt et al., 2006; Surprenant, 2007).

The cyclin-dependent kinase CdK5 plays an important role in pain transduction and nociceptive signaling (Pareek and Kulkarni, 2006; Pareek et al., 2006). Thr407 in TRPV1 can be directly phosphorylated by CdK5, whereas inhibition of CdK5 activity decreases TRPV1 function and $\mathrm{Ca}^{2+}$ influx. Interestingly, the CdK5 conditional knockout mouse shows hypoalgesia (Pareek et al., 2007).

A variety of 1,4-dihydropyridines have been developed as novel "enhancers" of TRPV1 activity. These compounds could increase the maximal capsaicin effect on ${ }^{45} \mathrm{Ca}^{2+}$ uptake in DRGs. The 1,4-dihydropyridine enhancers contain a 6-aryl substitution, alkyl groups at the 1 and 4 positions, and a 3-phenylalkylthioester (Roh et al., 2008).

General anesthetics [gas (e.g., isoflurane, sevoflurane, enflurane, and desflurane)] sensitize TRPV1 at clinically relevant concentrations in a process that can exacerbate postsurgical pain and inflammation (Cornett et al., 2008; Harrison and Nau, 2008). In addition, tramadol activates TRPV1, and it has been suggested that the "unexpected" local side effects of this analgesic (initiation of burning pain and erythema) are due to TRPV1-mediated local release of vasoactive neuropeptides (Marincsák et al., 2008).

\section{TRPV1 Antagonists}

The most advanced knowledge on the pharmacological modulation of a TRP channel has been obtained for TRPV1, because of the relevance of this protein for the management 
of chronic pain, migraine, and gastrointestinal disorders (Szallasi et al., 2007). As a result, numerous companies have initiated programs to discover TRPV1 modulators, identifying many novel and potent antagonists. Only the best-documented groups of synthetic antagonists are discussed here, dividing the various chemotypes into two major classes. The classic antagonists are characterized by the presence of a carbonyl group of the ester-, amide-, urea-, or thiourea-type that links two moieties, generally with different polarity. In the nonclassic antagonists, the carbonyl group is either present as part of a heterocyclic ring (e.g., 4-aminoquinazolines) or is unrecognizable.

Despite the structural heterogenicity of TRPV1 antagonists, a general model for their binding interaction with TRPV1 antagonists has been proposed (Szallasi et al., 2007). In brief, the unifying structural feature of TRPV1 antagonists is the presence of a central hydrogen-bond acceptor/ donor motif flanked by a lipophilic side chain on one side and a more polar aromatic group that incorporates a hydrogenbond acceptor on the other. A hydrogen-bonding motif is present in most known TRPV1 antagonist structures. In the classic antagonists, the central core can act as an H-bonding donor and acceptor, whereas in some nonclassic antagonists, it can only act as an H-bonding acceptor. In the polar arm, mono- or bicyclic-aryl and heteroaryl rings with a properly positioned hydrogen-bond acceptor are critical to both potency and drug-likeness. In the apolar arm, the placement of lipophilic substituents like a para-trifluoromethyl or a para$t$-butyl is crucial for potency, whereas the relevance of the aromatic ring in both arms is presumably related to the possibility of a $\pi-\pi$ interaction with the critical tyrosine group present in the vanilloid binding site.

Competitive Antagonists: Naturally Occurring TRPV1 Antagonists. TRPV1 antagonists are rare within natural products, in sharp contrast with the variety of agonists reported from the pool of secondary metabolites. This observation is consistent with an ecological role for the production of TRPV1 agonists in nature, in which these compounds seemingly act as a feeding deterrent. The naturally occurring TRPV1 antagonists discovered so far are structurally unrelated to the syn- thetic inhibitors and show only modest potency. The sesquiterpene lactone thapsigargin (23) is the irritant principle of Thapsia garganica L., a plant used in traditional and folk medicine as an anti-inflammatory agent. Thapsigargin behaves not only as an ultrapotent (subnanomolar) sarco(endo)plasmic reticulum $\mathrm{Ca}^{2+}$ ATPase inhibitor but also, paradoxically, as a TRPV1 antagonist (Table 2). No attempt has been made to dissect these activities and to assess the value of thapsigargin as a template to design TRPV1 antagonists (Tóth et al., 2002). Yohimbine (24), an indole alkaloid from the tree Pausinystalia yohimbe Pierre (formerly known as Corynanthe yohimbe K.) inhibits TRPV1 and the firing activity of DRGs exposed to capsaicin (Dessaint et al., 2004).

Endogenous TRPV1 Antagonists. Dynorphins, natural arginine-rich brain peptides that bind to $\kappa$-opioid receptors, are potent blockers of TRPV1, an activity that might contribute to their analgesic profile (Dessaint et al., 2004). Adenosine has also been proposed as an endogenous direct antagonist of TRPV1 (Puntambekar et al., 2004), whereas various dietary $\omega-3$ fatty acids like eicosapentaenoic and linolenic acids inhibit TRPV1 and might be beneficial for the treatment of pain (Matta et al., 2007). More recently, the endogenous fatty acid amide hydrolase inhibitor $N$-arachidonoyl serotonin (25) has been shown to cause a direct block of TRPV1 $\left(\mathrm{IC}_{50} \sim 40\right.$ $\mathrm{nM}$ ) and to inhibit the generation of anandamide. This dual effect represents a promising treatment against acute and chronic peripheral pain (Maione et al., 2007). Finally, polyamines have been reported to block TRPV1 channels. Thus, putrescine, spermidine, and spermine permeate TRPV1 with $P_{\mathrm{x}} / P_{\mathrm{Na}}$ values between 3 and 16 , and spermine reduced the single-channel conductance from 96 to $49 \mathrm{pS}$ (Ahern et al., 2006).

1,3-Di(arylalkyl)thioureas. The first identified competitive antagonist for TRPV1 was capsazepine (22; Table 2), a thiourea structurally related to capsaicin. Capsazepine competes for the capsaicin-binding site on TRPV1, inhibits capsaicinmediated channel activation, and can displace RTX from its binding site in radioligand bindings (Tominaga et al., 1998). Capsazepine emerged in the course of the Sandoz program aiming at the discovery of new vanilloid agonists, and its

TABLE 2

TRPV1 antagonists

\begin{tabular}{|c|c|c|c|c|c|}
\hline Group & Compound & Compound Number & $\mathrm{IC}_{50}$ & Species & Reference \\
\hline & & & $M$ & & \\
\hline \multirow[t]{2}{*}{ Naturally occurring } & Thapsigargin & 23 & $10^{-6}-10^{-5}$ & Rat & Tóth et al. (2002) \\
\hline & Yohimbine & 24 & $10^{-5}-10^{-4}$ & Rat & Dessaint et al. (2004) \\
\hline \multirow{3}{*}{ 1,3-Di(arylalkyl)thioureas } & Capsazepine & 22 & $10^{-7}-10^{-6}$ & Rodent & Caterina et al. (1997) \\
\hline & Compound & 26 & $10^{-5}$ & Rat & Lee et al. (2003) \\
\hline & JYL1421 & 27 & $10^{-8}$ & Rat & Wang et al. (2002) \\
\hline Iodinatede vanillyl derivatives & 5-iodoRTX & 11b & $10^{-9}$ & Rat & Wahl et al. (2001) \\
\hline \multirow{4}{*}{ Di(arylalkyl)- and aryl(arylakyl)ureas } & BCTC & 28 & $10^{-9}$ & Rat & Pomonis et al. (2003) \\
\hline & A-425619 & $29 a$ & $10^{-9}$ & Rat & McDonald et al. (2008) \\
\hline & SB-452533 & 31 & $10^{-8}-10^{-7}$ & Human & Rami et al. (2004) \\
\hline & ABT-102 & 32 & $10^{-9}$ & Human & Surowy et al. (2008) \\
\hline \multirow[t]{2}{*}{ Cinnamides } & SB-366791 & 33 & $10^{-9}$ & Human \& rat & Patwardhan et al. (2006) \\
\hline & AMG-9810 & 34 & $10^{-8}$ & Human \& rat & Doherty et al. (2005) \\
\hline \multirow[t]{2}{*}{ Carboxamides } & SB-782443 & 36 & $10^{-8}-10^{-7}$ & Human \& rat & Westaway et al. (2008b) \\
\hline & Compound & 38 & $10^{-8}-10^{-7}$ & Human \& rat & Westaway et al. (2008b) \\
\hline \multicolumn{6}{|l|}{ Nonclassic antagonists } \\
\hline \multirow[t]{2}{*}{ Imidazole derivatives } & Compound & 39 & $10^{-9}$ & Rat & Gore et al. (2007) \\
\hline & AMG517 & 40 & $10^{-10}$ & Rat & Gavva et al. (2007) \\
\hline \multirow[t]{3}{*}{ Noncompetitive } & Ruthenium Red & & $10^{-7}$ & Rat & García-Martínez et al. (2000) \\
\hline & AG 489 & $41 \mathrm{a}$ & $10^{-8}$ & Rat & Kitaguchi and Swartz (2005) \\
\hline & DD161515 & 43 & $10^{-7}-10^{-6}$ & Rat & García-Martínez et al. (2002) \\
\hline
\end{tabular}


discovery was therefore serendipitous. This program, to date the most comprehensive one focusing on capsaicin, was based on the recognition that the structure of this natural alkaloid can be divided into three moieties: the aromatic and hydrogen bonding $\mathrm{A}$ ring, the lipophilic $\mathrm{C}$ tail, and the carbonyl-containing B-linker (Suh and Oh, 2005). In principle, capsazepine can be considered as a conformationally restricted capsaicin analog in which the amide bond of the natural product is replaced by a thiourea moiety and in which the presence of a tether between the aromatic A ring and the B-linker forces the catecholic aromatic moiety into an orthogonal orientation with respect to the thiourea bond. Pharmacological studies showed that capsazepine exhibited low metabolic stability and poor pharmacokinetic properties in rodents, thus preventing its clinical development (Walker et al., 2003). The tether was not critical for activity, because powerful capsaicinoid antagonists devoid of this structural feature were developed, with 1,3-di(arylalkyl)thioureas emerging as one of the most promising nonvanilloid class of TRPV1 antagonists. These compounds are endowed with excellent therapeutic potential in pain regulation, with an $\mathrm{IC}_{50}$ value generally lower than $100 \mathrm{nM}$ (Suh and Oh, 2005; Suh et al., 2005; Chung et al., 2007). Within these compounds, the replacement of the guaiacyl moiety of capsaicinoids with a 3-fluoro-4-sulfonylamido group was critical to revert biological activity. This, coupled to the design of C-region moiety mimicked on RTX, led eventually to compound $\mathbf{2 6}$ (Table 2), a high-affinity TRPV1 antagonist that showed excellent analgesic activity in mice (Lee et al., 2003, 2005). An alternative optimization of the lipophilic $\mathrm{C}$ region led to JYL1421 (27, Table 2), another promising clinical candidate (Wang et al., 2002).

Iodinated Vanillyl Derivatives. Although RTX is an ultrapotent agonist for TRPV1, the introduction of an iodine atom ortho to the phenolic hydroxyl of the homovanillyl moiety reverts its biological activity, generating the powerful antagonist 5-iodoRTX (11b; Table 2) (Wahl et al., 2001). However, enthusiasm for 5-iodoRTX as a TRPV1 antagonist was later tempered by the observation that 5-iodoRTX can still activate TRPV1, possibly because of partial agonism, in vivo deiodination to RTX (Shimizu et al., 2005), or the presence 6-iodoRTX (11c) as an impurity (Ech-Chahad et al., 2006). It is noteworthy that 6-iodoRTX is a partial agonist, whereas aromatic iodination either in 5 or in 6 of capsaicin and in 6 of phenylacetylrinvanil led to a reversal of activity, generating TRPV1 antagonists (Appendino et al., 2005a). These observations show that the introduction of iodine at the 6-position is a general maneuver to revert the activity of capsaicinoids, although the molecular details of this remarkable effect are unknown.

Di(arylalkyl)- and Aryl(arylakyl)ureas. This structural template has been intensively investigated as a source of TRPV1 antagonists, and only the most advanced compounds in the class are discussed here. A series of capsaicin analogs of the urea type were developed by acylation of homovanillylamine and related amines with different 4 -( $\alpha$-pyridyl)piperidine-1-acyl chlorides. The presence of a polar amino moiety in the hydrophobic $\mathrm{C}$ region of capsacinoids was crucial to couple potency and hydrophilicity, mimicking similar observations that led to the discovery of phenylacetylrinvanil from olvanil. Several other ureas emerged as remarkably active TRPV1 antagonists. Compared with capsazepine, the piperazinyl urea (28, BCTC; Table 2) showed a higher selectivity profile against a wide variety of enzymes and channels (Pomonis et al., 2003), whereas the related very potent and specific TRPV1 antagonist A-425619 (29) (Table 2) could attenuate pain associated with inflammation and tissue injury in rats, showing two-digit nanomolar $\mathrm{IC}_{50}$ values in dorsal root ganglia and trigeminal ganglia and high efficiency in blocking capsaicin- and NADA-evoked secretion of CGRP (McDonald et al., 2008).

Further research has led to a variety of small-molecule antagonists of TRPV1, including the ureas SB-705498 (30), SB-452533 (31) (Rami et al., 2004, 2006), and ABT-102 (32, see Table 2 for details), a compound that has entered clinical trials. Finally, replacement of substituted benzyl groups with an indan rigid moiety in a previously described $N$-indazole$N^{\prime}$-benzyl urea antagonist has led to compounds with significantly increased in vitro potency and enhanced drug-like properties (Surowy et al., 2008).

Cinnamides. $N$-Arylcinnamides have emerged as potent as an important class of TRPV1 antagonists, endowed with high potency $\left(\mathrm{IC}_{50} \leq 10^{-6} \mathrm{M}\right.$ for SB-366791, 33) (Table 2), competitive and specific activity in both human and rat TRPV1 receptors, and an overall profile of receptor selectivity much better than that of capsazepine (Gunthorpe et al., 2004; Patwardhan et al., 2006). Within this series of compounds, AMG9810 (34) exhibited high antagonist potency $\left(\mathrm{IC}_{50} \sim 10^{-5} \mathrm{M}\right)$ and was assayed in a series of in vivo experiments, showing good oral bioavailability in rats and a promising pharmacokinetic profile (Doherty et al., 2005), boding well for clinical efficacy. Another potent blocker from this group is AMG0347 (35) (Wu et al., 2008), that was shown in a postoperative pain trial to be able to decrease capsaicin-induced heat and mechanical hyperalgesia and to block central TRPV1 receptors.

Carboxamides. Several TRPV1 antagonists of the carboxamide type have been discovered. These compounds show $\mathrm{IC}_{50}$ values in the 10 to $100 \mathrm{nM}$ range and are structurally quite heterogenous, as exemplified by comparison of the nicotinamide derivative SB-782443 (36), the thiazolylcarboxamide (37), and the tetrahydropyridylcarboxamide (38) (Westaway et al., 2008a) (Table 2). SB-782443 (36) showed excellent potency at human, guinea pig, and rat TRPV1, a favorable in vitro Drug Metabolism and Pharmacokinetics profile, and remarkable in vivo activity in an inflammatory pain model (Westaway et al., 2006; Brown et al., 2008). Based on their in vitro profile, several compounds of this class qualified for preclinical development (Westaway et al., 2008a).

Competitive Antagonists: Nonclassic TRPV1 Antagonists. Nonclassic antagonists lack the urea, thiourea, or amide groups typical of the classic TRPV1 ligands. Two major structural types of nonclassic antagonists have been discovered.

Imidazole Derivatives. Starting from a 4,6-disubstituted benzimidazole lead structure, a series of 4,5-biarylimidazoles capable to block both capsaicin- and acid-induced calcium influx in TRPV1-expressing Chinese hamster ovary cells were obtained. Imidazole (39) was identified as a highly potent $\left(\mathrm{IC}_{50} \sim 10^{-9} \mathrm{M}\right)$ and orally bioavailable TRPV1 antagonist worthy of further development (Gore et al., 2007).

Diaryl Ethers and Amines. Compounds from the quinazoline series can be considered as conformationally restricted analogs of a biarylamide series (Table 2). A series of hetero- 
cyclic cores was investigated, ranked in terms of activity in this sequence: 5 -isoquinoline $>8$-quinoline $=8$-quinazoline $>8$-isoquinoline $>$ or $=$ cinnoline $\approx$ phthalazine $\approx$ quinoxaline $\approx 5$-quinoline (Blum et al., 2008). Of particular relevance is AMG517 (40), a compound that lacks any recognizable carbonyl motif. This compound potently blocks capsaicin, proton, and heat activation of TRPV1 in vitro, inhibits capsaicin-induced flinch in rats in vivo, and shows, apart from hyperthermia, a good tolerability profile (Gavva et al., 2007).

Noncompetitive Antagonists (Pore Blockers). Ruthenium red (RR) is a noncompetitive pan inhibitor of all TRP channels. This compound presumably interacts not only with the ligand binding site of TRPs but apparently also blocks its aqueous pore. RR binds TRPV1 with high potency (Table 2) in a voltage-dependent manner (i.e., inward currents are efficiently blocked but not outward currents) (García-Martínez et al., 2000). Commercial RR is a mixture of various ruthenium derivatives, but surprisingly, its active component has not yet been characterized. Tetrabutylammonium (TBA) blocks the conductions pore of TRPV1. TBA belongs to a family of classic potassium channel blockers that have been widely used as tools for determining the localization of the activation gate and the properties of the pore of several ion channels. TBA blocks TRPV1 in a voltage-dependent fashion, consistent with being an open-state blocker and interfering with the closing of an activation gate located cytoplasmically (Oseguera et al., 2007). Indeed, TRPV1 is permeable to organic cationic dyes and aminoglycoside antibiotics, suggesting the existence of a large pore (Meyers et al., 2003; Myrdal and Steyger, 2005). The pore block and the divalent permeability of TRPV1 depend on the negatively charged residues described above within the pore region of the protein (GarcíaMartínez et al., 2000).

Robust TRPV1 inhibitory activity was found in the venom from the North American funnel web spider, Agelenopsis aperta. Fractionation of the venom resulted in the purification of two acylpolyamine toxins, AG489 and AG505 (41a and 41b, respectively), which both inhibit TRPV1 channels from the extracellular side of the membrane. AG489 (Table 2) was found to inhibit TRPV1 in a voltage-dependent way, with relief from inhibition being observed at positive voltages, an observation consistent with a model in which the toxin inhibits the channel through a pore-blocking mechanism $\left(\mathrm{IC}_{50}\right.$ $\sim 33 \mathrm{nM}$ at $-40 \mathrm{mV}$ ). Negatively charged residues in the pore vestibule have indeed been identified as the AG489 binding site. Mutations of these site (Glu636, Asp646, Glu651, and Asn628) result in weakening of the block, whereas mutations of Tyr627 and Cys636 in the pore region enhance the toxin affinity (Kitaguchi and Swartz, 2005).

Because arginine-rich hexapeptides like RRRRWW-NH $\mathrm{NH}_{2}$ block TRPV1 channels expressed in Xenopus laevis oocytes in a nonselective manner (Himmel et al., 2002), various polymethylene tetraamines were investigated as TRPV1 channel blockers. These studies identified methoctramine (42), a muscarinic M2 receptor antagonist, as a noncompetitive capsaicin antagonist with an $\mathrm{IC}_{50}$ value of $2 \mu \mathrm{M}$ and notable voltage-dependent block (Mellor et al., 2004). Finally, screening of a library of tripeptoid $N$-alkylglycines identified DD161515 (43, Table 2) and DD191515 as TRPV1 blockers with micromolar potency and moderate voltage-dependence (García-Martínez et al., 2002).

An interesting mechanism of analgesia has been developed capitalizing on TRPV1 pore permeability. Thus, the membrane-impermeable $\mathrm{Na}^{+}$channel blocker QX-314 can permeate cells through capsaicin-activated TRPV1. Under these conditions, it can block from the inner site the $\mathrm{Na}^{+}$channels in DRG neurons, preventing the generation of an action potential, and behaving as a long-lasting analgesic (Binshtok et al., 2007).

\section{TRPV2}

TRPV2 has been proposed as a potential pain target both for its sequence similarity to TRPV1 (50\% identical) and for its activation by noxious high temperatures $\left(>52^{\circ} \mathrm{C}\right)$ (Caterina et al., 1999). This view is supported by the finding that TRPV2 is widely expressed in medium to large diameter A $\delta$ mechanosensitive and thermosensitive neurons in the rat dorsal root ganglia (Caterina et al., 1999), trigeminal ganglia (Ichikawa and Sugimoto, 2000), and the spinal cord (Lewinter et al., 2004).

\section{TRPV2 Agonists}

TRPV2 is activated by noxious heat, with an activation threshold greater than $52^{\circ} \mathrm{C}$ (Caterina et al., 1999) and by a number of exogenous chemical ligands, but ligand and thermal activation show species specificity. For example, although noxious heat (up to $53^{\circ} \mathrm{C}$ ) and the nonselective agonist 2-APB activate rat and mouse TRPV2, human TRPV2 does not respond to 2-APB (up to $1 \mathrm{mM}$ ) or to elevated temperatures (up to $53^{\circ} \mathrm{C}$; (Neeper et al., 2007). Analysis of chimeric constructs of mouse and human TRPV2 channels showed that the molecular determinants of 2-APB sensitivity are localized in the intracellular $\mathrm{N}$ and $\mathrm{C}$ termini. Further experiments showed that human TRPV2 exerts, with an unknown mechanism, a dominant-negative effect on 2-APB activation of native rodent TRPV2 channels (Juvin et al., 2007). Another phenylborate, DPBA, is also able to activate mouse TRPV2 with similar $\mathrm{EC}_{50}$ values (Juvin et al., 2007). Rat TRPV2 is activated by the uricosuric agent probenecid (44; Table 3), and five other sensory thermoTRPs (TRPV1,

TABLE 3

TRPV2 activators and inhibitors

$\mathrm{EC}_{50}$ and $\mathrm{IC}_{50}$ values are given in column with concentration range.

\begin{tabular}{|c|c|c|c|c|c|}
\hline Group & Compound & Compound Number & Conc. $\mathrm{R}$ & Species & Reference \\
\hline & & & $M$ & & \\
\hline \multirow[t]{4}{*}{ Activators } & Probenecid & 44 & $10^{-5}$ & Rat & Bang et al. (2007) \\
\hline & Cannabidiol & 45 & $10^{-6}$ & Human and rat & Qin et al. (2008) \\
\hline & THC & 46 & $10^{-5}$ & Human and rat & Qin et al. (2008) \\
\hline & Cannabidiol & 47 & $10^{-4}$ & Human and rat & Qin et al. (2008) \\
\hline Inhibitors & SKF96365 & 48 & $10^{-5}$ & Mouse & Juvin et al. (2007) \\
\hline
\end{tabular}


TRPV3, TRPV4, TRPM8, and TRPA1) failed to show a response to this drug (Bang et al., 2007). Very recently, several novel cannabinoid rat TRPV2 modulators were identified. Cannabidiol (45), a nonpsychotropic compound, was found to be a more robust and potent agonist $\left(\mathrm{EC}_{50} \sim 4 \mu \mathrm{M}\right)$ than the psychotropic agent $\Delta^{9}$-tetrahydrocannabinol (46), the main psychoactive substance found in Cannabis sativa L. $\left(\mathrm{EC}_{50}\right.$ $\sim 14 \mu \mathrm{M}$ ) and cannabinol (47, $\mathrm{EC}_{50} \sim 78 \mu \mathrm{M}$ ) (Table 3) (Qin et al., 2008). TRPV2 has been proposed as a potential pain target, but very little is known about its activation mechanism or possible candidates for specific or endogenous TRPV2 activators.

Sensitizers. Although no selective exogenous or endogenous activators of TRPV2 have been identified to date, evidence has been growing that translocation may be an important mechanism for TRPV2 functional activation. Growth factors up-regulate TRPV2 expression and function by promoting its translocation from the intracellular pools to the plasma membrane, in which it demonstrates constitutive activity (e.g., insulin-like growth factor-1) (Kanzaki et al., 1999; Boels et al., 2001; Iwata et al., 2003). Heat and phosphatidylinositol-3 (PI3) kinase also promote TRPV2 membrane insertion, whereas PI3 kinase inhibition reduces TRPV2 membrane insertion (Penna et al., 2006). In accordance with this scenario, the PI3 kinase inhibitors LY2934001 ${ }^{1}$ could block the translocation of TRPV2 to the plasma membrane (Nagasawa et al., 2007).

\section{TRPV2 Antagonists}

Despite the possible role of TRPV2 as a potential pain target, few specific blockers have been identified yet. Some general blockers like RR and trivalent cations such as $\mathrm{La}^{3+}$ and $\mathrm{Gd}^{3+}$ have been described as blockers of TRPV2 (Leffler et al., 2007). SKF96365 (48) and the diuretic amiloride (49) also behave as efficient blockers (Table 3). In addition, the potassium channel blockers tetraethylammonium, 4-aminopyridine, and 1-(2-(trifluoromethyl)phenyl) imidazole were all found to inhibit TRPV2 activation (Juvin et al., 2007). Also the monoterpene aldehyde citral (50) inhibited, in a voltage-independent way, the 2-APB-evoked activity of TRPV2 $\left(K_{\mathrm{d}} \sim 534 \mu \mathrm{M}\right)$ (Stotz et al., 2008).

\section{TRPV3}

TRPV3 was cloned by using its sequence homology to other heat-activated TRP channels, and shares $40 \%$ identity with

\footnotetext{
${ }^{1}$ The structures of compounds LY2934001, HC-01403, GRC 15133, GRC 17173 , and RN-9893 have not been disclosed in the public literature and are found only in patent applications currently under examination and not available for inspection. Therefore, unless and until these structures are made public, it is impossible to independently verify or replicate results associated with those compounds.
}

TABLE 4

TRPV3 activators

\begin{tabular}{|c|c|c|c|c|c|}
\hline Group & Compound & Compound Number & $\mathrm{EC}_{50}$ & Species & Reference \\
\hline & & & $M$ & & \\
\hline \multirow[t]{7}{*}{ Activators } & Camphor & 13 & $10^{-4}-10^{-2}$ & Human and mouse & Moqrich et al. (2005) \\
\hline & Thymol & 51 & $10^{-4}$ & Human and mouse & $\mathrm{Xu}$ et al. (2006) \\
\hline & Menthol & 53 & $10^{-4}-10^{-3}$ & Murine & Macpherson et al. (2006) \\
\hline & Eugenol & 9 & $10^{-5}-10^{-3}$ & Human and mouse & $\mathrm{Xu}$ et al. (2006) \\
\hline & Vanillin & $52 \mathbf{a}$ & $10^{-2}-10^{-1}$ & Human and mouse & $\mathrm{Xu}$ et al. (2006) \\
\hline & Incensole acetate & 54 & $10^{-5}$ & Mouse & Moussaieff et al. (2008) \\
\hline & $2-\mathrm{APB}$ & & $10^{-6}$ & Mouse & Chung et al. (2004) \\
\hline
\end{tabular}

TRPV1. TRPV3 shows threshold in the physiological temperatures range of 32 to $39^{\circ} \mathrm{C}$ and can also be activated by 2-APB and camphor (13) (Nilius and Mahieu, 2006). In humans, TRPV3 has been reported to be present in pain pathways, including DRG and TG neurons, spinal cord, keratinocytes, and brain (Xu et al., 2002). However, in mouse and rat, the distribution of TRPV3 is more controversial (Peier et al., 2002).

\section{TRPV3 Agonists}

TRPV3 is highly expressed in the skin, tongue, and nose (Xu et al., 2002) and is the target for several plant-derived aromatic agents and for skin sensitization. TRPV3 is activated by a number of exogenous ligands, including natural irritants [e.g., camphor (13); Moqrich et al., 2005), thymol (51) from thyme, and eugenol (9) from clove] and might be involved in the anesthetic, analgesic, and antipruritic properties of these compounds (Vogt-Eisele et al., 2007) (Table 4). Vanillin (52a), the active ingredient of vanilla (Vanilla planifolia Jacks. ex Andrews), weakly activates TRPV3, whereas the synthetic flavor ethylvanillin $(\mathbf{5 2 b})$, the homolog of the natural product, activates TRPV3 much more potently (Xu et al., 2006). Surprisingly, a recent report showed that menthol (53) from peppermint (Mentha piperita L.), a popular cooling agent and TRPM8 activator, also binds to and activates TRPV3 (Vogt-Eisele et al., 2007). The disinfectant cresol (methylphenol) also activates TRPV3. Solutions of this simple phenol are used as household cleaners and disinfectants, perhaps most famously under the trade name Lysol (Reckitt Benckiser, Parsippany, NJ). Cresol was also promoted as a disinfecting vaginal douche in mid-20th century America. It also occurs in foods, wood and tobacco smoke, crude oil, and coal tar (Vogt-Eisele et al., 2007).

The cembrane diterpenoid incensole acetate (54), a constituent of frankincense, is a potent TRPV3 agonist that causes anxiolytic-like and antidepressive-like behavioral effects in wild-type mice (Table 4). These behavioral effects were not evidenced in $\mathrm{TRPV}^{-1-}$ mice. Incensole acetate activates TRPV3 channels also in native keratinocytes, but only modest effects were observed on TRPV1, TRPV2, and TRPV4 (Moussaieff et al., 2008). The synthetic compounds 2-APB and diphenylboronic anhydride (DPBA) can also activate TRPV3. In single-channel analysis of inside-out membrane patches excised from TRPV3-expressing cells, $1 \mu \mathrm{M} 2$-APB evoked single-channel openings (Chung et al., 2004). The 2-APB analog DPBA and 2,2-diphenyltetrahydrofuran (DPTHF) also influences TRPV3. DPBA activates TRPV3 in a similar manner as 2-APB (Table 4), whereas DPTHF has an opposite action, blocking TRPV3. Apparently, a structural feature important for activation of TRPV3 lacks in DPTHF, 
resulting in inhibition even though it binds to a "stimulatory site" (Chung et al., 2005).

Very recently, evidence was found that 2-APB activation of TRPV3 is separable from other activation mechanisms and depends on two cytoplasmic residues (Hu et al., 2009). Thus, $\mathrm{Hu}$ and coworkers (2009) found two residues (His426 and Arg696) specifically required for sensitivity of TRPV3 to 2 -APB but not to camphor or voltage (Hu et al., 2009). Chicken TRPV3 is weakly sensitive to $2-\mathrm{APB}$, and the equivalent residue at 426 is an asparagine. Mutating this residue to histidine induced 2-APB sensitivity of chicken TRPV3 to levels comparable with those of other TRPV3 orthologs. The cytoplasmic C-terminal mutation R696K in the TRP box displayed 2-APB-specific deficits only in the presence of extracellular calcium, suggesting involvement in gating. Mutating these two residues in TRPV4, a 2-APB-insensitive channel, to TRPV3 sequences was sufficient to induce TRPV3-like 2-APB sensitivity (Hu et al., 2009).

Sensitizers. TRPV3 is also sensitized and/or directly activated by endogenous ligands, including downstream elements of the inflammatory cascade, such as unsaturated fatty acids (e.g., arachidonic acid) and protein kinases (e.g., PKC) (Hu et al., 2006). TRPV3 would be expected to be basally active at body temperature. However, TRPV3 activity may be further enhanced under inflammatory conditions.

\section{TRPV3 Antagonists}

There are very few potent and selective inhibitors of TRPV3. The TRPV3 antagonist HC-001403 has been reported to be active in animal models of pain, like the rat complete Freund's adjuvant inflammatory hyperalgesia, the formalin-induced flinching assay, and the thermal injury pain (Moran et al., 2007). Two other antagonists were recently reported. These compounds (GRC 15133 and GRC 17173) displayed potency in the low $100 \mathrm{nM}$ range, with excellent selectivity in terms of TRPs binding and efficacy in inflammatory and nerve injury models (Gullapalli et al., 2008).

\section{TRPV4}

TRPV4 functions as a $\mathrm{Ca}^{2+}$-entry channel that exhibits a surprising gating promiscuity. The channel can be activated by physical stimuli (cell swelling and innocuous warmth, $\sim 27-35^{\circ} \mathrm{C}$ ) and by chemical ligands. Endogenous chemical ligands (e.g., endocannabinoids and arachidonic acid metabolites) and small-molecule exogenous ligand from the pool of natural products (e.g., bisandrographolide A, 55), natural product derivatives (e.g., $\alpha$-phorbol esters, 56a-d), and fully synthetic compounds (e.g., GSK1016790A, 57) have been identified. TRPV4 is widely expressed in brain, central nervous system, kidney, bladder, vascular endothelium, keratin- ocytes, and multiple excitable and nonexcitable peripheral cell types (Nilius et al., 2004).

\section{TRPV4 Agonists}

TRPV4 was originally identified as a channel activated by hypotonic cell swelling (Liedtke et al., 2000; Strotmann et al., 2000; Wissenbach et al., 2000; Nilius et al., 2001b). Activation of TRPV4 by cell swelling is caused by PLA2 activation (Watanabe et al., 2003; Vriens et al., 2005). PLA2-mediated release of arachidonic acid from membrane lipids and subsequent metabolization of arachidonic acid by cytochrome P450 epoxygenase activity leads to the formation of epoxyeicosatrienoic acids (EETs), which activate TRPV4 in a membranelimited manner. Given the high ligand sensitivity, it does not seem unreasonable to assume that TRPV4 has also endogenous ligands, but none of them has so far been identified (Nilius et al., 2003, 2004; Watanabe et al., 2003; Vriens et al., 2005).

Phorbol esters, like $4 \alpha$-PDD (56a), bind TRPV4 in a very specific (lack of response in TRPV4-deficient mice; Vriens et al., 2005) and membrane-delimited manner (Watanabe et al., 2002; Vriens et al., 2004b). Activation by $4 \alpha$-PDD is slow, suggesting that diffusion in the cell might be rate-limiting. In line with an intracellular mode of action, application of $4 \alpha-$ PDD from the cytoplasmic side of inside-out patches activates TRPV4. A tyrosine-serine motif located in the intracellular loop between the second and third transmembrane domain determines the responsiveness to $4 \alpha$-PDD but not to hypotonic solutions or arachidonic acid. Furthermore, mutations of two hydrophobic residues in the central part of TM4 (Leu584 and Trp586) caused a severe reduction of the sensitivity of the channel to $4 \alpha$-PDD and heat, whereas responses to cell swelling, arachidonic acid, and 5,6-EET remained unaffected. Conversely, the mutation of two residues in the C-terminal region of TM4 (Tyr591 and Arg594) affected channel activation of TRPV4 by all stimuli, suggesting an involvement in channel gating rather than in interaction with ligands. Comparison of the responses of wild-type and mutant TRPV4 with a series of $4 \alpha$-phorbol diesters established a critical role for the length of the acyl moiety that is optimal for 6 and 10 carbons (Vriens et al., 2007) (Table 5). The $4 \alpha$-configuration is apparently not essential for channel activation because $4 \beta$-PDD (56b) could activate TRPV4 with potency similar to that of $4 \alpha$-PDD (Nilius et al., 2004), whereas phorbol-12-myristate-13-acetate (PMA, 58), the archetypal tumor-promoting PKC activator, could activate TRPV4, albeit with a 10 - to 50 -fold lower potency than $4 \alpha$ PDD. In sharp contrast to the structure-activity relationships for PKC activation by phorbol esters, removal of the 4-hydroxyl and conversion to cage compounds from the lumiseries were not critical for the activity of $4 \alpha$-phorbol diesters.

TABLE 5

TRPV4 activators

\begin{tabular}{|c|c|c|c|c|c|}
\hline Group & Compound & Compound Number & $\mathrm{EC}_{50}$ & Species & Reference \\
\hline & & & $M$ & & \\
\hline \multirow[t]{5}{*}{ Activators } & Arachidonic Acid & & $10^{-5}$ & Mouse & Watanabe et al. (2003) \\
\hline & 5,6 -EET & & $10^{-6}$ & Mouse & Watanabe et al. (2003) \\
\hline & BAA & 55 & $10^{-7}-10^{-6}$ & Mouse & Smith et al. (2006) \\
\hline & $4 \alpha-\mathrm{PDD}$ & $56 \mathbf{a}$ & $10^{-6}$ & Mouse & Watanabe et al. (2002) \\
\hline & GSK10116790A & 57 & $10^{-9}-10^{-8}$ & Human and mouse & Thorneloe et al. (2008) \\
\hline
\end{tabular}


Conversely, two ester groups of similar length were necessary for activity (Vriens et al., 2007).

TRPV4 is also activated by the dimeric diterpenoid bisandrographolide A (BAA, 55) (Table 5) from the Indian medicinal plant Andrographys paniculata. BAA functions also in cell-free inside-out patches, indicating a membrane-delimited action (Smith et al., 2006). Evidence was provided that the TM3 to TM4 region of TRPV4 forms an important site for channel activation by BAA. In particular, mutations at positions Leu584 and Trp586 in TM4 strongly affect channel activation by BAA (Vriens et al., 2007).

A novel very potent activator for TRPV4 has been reported (GSK1016790A, 57) (Thorneloe et al., 2008). This compound produced dramatic and complex cardiovascular effects associated with endothelial barrier failure, eventually leading to circulatory collapse, in mouse, rat, and dog (Willette et al., 2008). TRPV4 is highly expressed in the endothelium, where it is involved in intracellular $\mathrm{Ca}^{2+}$ homeostasis and the regulation of cell volume (Vriens et al., 2005). The discovery that its inappropriate activation leads to massive disruption of microvascular permeability suggests that TRPV4 might be associated with edema and microvascular congestion.

Sensitizers. TRPV4 can be sensitized to activation by proteases generated under inflammation conditions, like the PAR2. PAR2 agonists sensitize activation of TRPV4 by $4 \alpha-$ PDD and hypotonic cell swelling probably via PLC $\beta$, PKA, PKC, and protein kinase D (Grant et al., 2007; Surprenant, 2007).

In native ciliated epithelial cells, the PLA2-EET primary pathway and the PLC pathway, both activated by ATP, cooperate and support TRPV4 gating, whereas $\mathrm{IP}_{3}$, per se, not an agonist, sensitizes TRPV4 to EET. Coimmunoprecipitation assays indicated a physical interaction between TRPV4 and $\mathrm{IP}_{3} \mathrm{R} 3$. TRPV4 channels and intracellular store $\mathrm{Ca}^{2+}$ channels are both required to initiate and maintain the oscillatory $\mathrm{Ca}^{2+}$ signal triggered by high viscosity and hypotonic stimuli that do not reach a threshold level of PLA2 activation (Fernandes et al., 2008).

\section{TRPV4 Antagonists}

Besides the classic TRP inhibitors RR that reversibly inhibits inward but not outward TRPV4 currents (Watanabe et al., 2002), $\mathrm{Gd}^{3+}$, and $\mathrm{La}^{3+}$, two new TRPV4 antagonists with micromolar (RN-1734) and nanomolar (RN-9893) potency with selectivity versus other thermo-TRPs, were described. $\mathrm{RN}-9893$ was also reported to possess good pharmacokinetic properties, but no in vivo data have been published (Broad et al., 2009). Citral (50) from lemongrass oil, a compound commonly used to repel insects, inhibits TRPV4 activity in a voltage-independent way ( $\left.\mathrm{IC}_{50} \sim 32 \mu \mathrm{M}\right)$ (Stotz et al., 2008).

\section{TRPV5 and TRPV6}

Compared with TRPV1-V4, TRPV5 and its highly homologous TRPV6 are only distantly related, as evident from the phylogenic tree depicted in Fig. 1. Unsurprisingly, they also show somewhat different functional properties, whose hallmark is the high $\mathrm{Ca}^{2+}$ selectivity. Expression profiling of TRPV5 and TRPV6 showed expression in kidney, small intestine, placenta, prostate, pancreas, salivary gland, brain, colon, and rectum (Hoenderop et al., 1999). In general, TRPV5 expression seems to be typical of kidney, whereas
TRPV6 is predominantly expressed in small intestine and prostate (Hoenderop et al., 2000). Currents through TRPV5 and TRPV6 are strongly inwardly rectified and highly $\mathrm{Ca}^{2+}$. selective $\left(P_{\mathrm{Ca}} / P_{\mathrm{Na}}>100\right)$.

\section{TRPV5 and TRPV6 Agonists}

No direct activator of TRPV5 and TRPV6 has so far been identified. TRPV5 and TRPV6 channels are constitutively active when inserted into the plasma membrane. Regulation most probably occurs by variation of the channel density on the plasma membrane. Expression of TRPV5 is influenced by 1,25-dihydroxy vitamine D3 (Yamauchi et al., 2005), the $\mathrm{Ca}^{2+}$ binding protein S100A10, and annexin II (van de Graaf et al., 2006). Calmodulin binds to both TRPV5 and TRPV6 in a $\mathrm{Ca}^{2+}$-dependent fashion (Lambers et al., 2004) and supports, at least, the activation of TRPV6. Extracellular alkalization causes TRPV5 accumulation in subplasmalemmal vesicles. From this pool, TRPV5 can be rapidly recruited into the plasma membrane (Lambers et al., 2007).

An important regulatory pathway comprises the tissue serine protease kallikrein. Kallikrein activates the bradykinin receptor-2, which in turn activates PKC dependently on diacylglycerol via PLC $\beta$. Phosphorylation of TRPV5 increases membrane insertion of the channel and delays retrieval (Gkika et al., 2006). The PKC activator 1-oleoyl-acetyl-sn-glycerol (OAG) also increased TRPV5 surface abundance. The OAG-mediated increase of TRPV5 was prevented by preincubation with specific PKC inhibitors. Knockdown of caveolin-1 also prevented the increase of TRPV5 by OAG. Parathyroid hormone (PTH) increased TRPV5 current density in cells coexpressing TRPV5 and type 1 PTH receptor. The increase caused by PTH was prevented by PKC inhibitor, mutation of Ser299/Ser654, or knockdown of caveolin-1. This mechanism of regulation by PKC may contribute to the short-term stimulation of TRPV5 and renal $\mathrm{Ca}^{2+}$ reabsorption by PTH (Cha et al., 2008).

TRPV5 is highly regulated by WNK4, a protein serine/ threonine kinase whose gene mutations cause familial hyperkalemic hypertension. Expression of WNK4 increases surface expression of TRPV5 and therefore modulates calcium reabsorption mediated by this channel (Jiang et al., 2007).

The pro-urine hormone klotho can stimulate TRPV5 and TRPV6 by $N$-oligosaccharide hydrolysis. Klotho is a $\beta$-glucuronidase that hydrolyzes extracellular sugar residues on TRPV5, entrapping the channel in the plasma membrane. Klotho effects are primarily restricted to the epithelial $\mathrm{Ca}^{2+}$ channels TRPV5 and TRPV6 (Chang et al., 2005; Schoeber et al., 2007; Lu et al., 2008).

\section{TRPV5 and TRPV6 Antagonists}

The most effective inhibitors of currents through TRPV5 described so fare are RR and the antifungal azole econazole (59), with $\mathrm{IC}_{50}$ values between 0.1 and $1 \mu \mathrm{M}$. The divalent cation current block profile for TRPV5 is $\mathrm{Pb}^{2+}=\mathrm{Cu}^{2+}>$ $\mathrm{Zn}^{2+}>\mathrm{Co}^{2+}>\mathrm{Fe}^{2+}$, with $\mathrm{IC}_{50}$ values between 1 and approximately $10 \mu \mathrm{M}$ (Nilius et al., 2001a). It is noteworthy that TRPV6 can be blocked by RR but has a 100-fold lower affinity for $\mathrm{RR}\left(\mathrm{IC}_{50} \sim 9 \mu \mathrm{M}\right)$ than TRPV5 (Nilius et al., 2001a). $\mathrm{Ca}^{2+}$-induced inactivation occurs at hyperpolarized potentials in the presence of extracellular $\mathrm{Ca}^{2+}$. Half-maximal inactivation by $\left[\mathrm{Ca}^{2+}\right]_{\mathrm{i}}$ occurs at a concentration of $\sim 100$ nM. TRPV6 is $\mathrm{Ca}^{2+}$-dependently inactivated, a process trig- 
gered by $\mathrm{Ca}^{2+}$-dependent PLC activation and depletion of PIP2. U73122 and edelfosine induce sustained TRPV6 activation in a duodenal sac assay. Thus, PLC modulators can be used as novel TRPV6 $\mathrm{Ca}^{2+}$ reabsorption modulators (Thyagarajan et al., 2009).

Blockade of TRPV5 and TRPV6 by extracellular $\mathrm{Mg}^{2+}$ is voltage-dependent and critically depends on a single aspartate residue in the selectivity filter of the TRPV5/6 pore. Intracellular $\mathrm{Mg}^{2+}$ also exerts a voltage-dependent block that is alleviated by hyperpolarization and contributes to the time-dependent activation and deactivation of TRPV6-mediated monovalent cation currents (Voets et al., 2001, 2003).

TRPV5 is inhibited by binding protons to the extracellular Glu522. In addition, mutation of the pore helix residue E535Q further enhances inhibition by $\mathrm{H}^{+}$by shifting the $\mathrm{pKa}$ value for inhibition toward more alkaline values. This mechanism may contribute to hypercalciuria with high acid load (Yeh et al., 2006).

TRPV6 interacts with the protein tyrosine phosphatase 1B and is probably inhibited by $\mathrm{Ca}^{2+}$ via an intermediate reactive oxygen species. Inhibition of tyrosine dephosphorylation by protein tyrosine phosphatase $1 \mathrm{~B}$ inhibition causes a maintained $\mathrm{Ca}^{2+}$ influx via TRPV6, thus inducing a positive feedback (Sternfeld et al., 2005; Bogeski et al., 2006).

\section{Conclusion}

Ion channels of the TRPV subfamily form an important aspect of the sensory mechanism of animals. Indeed, it has been shown that one part of the TRPV subfamily, namely TRPV1 to TRPV4, reacts to thermal, mechanical, and/or painful stimuli. The properties as nociceptors qualify TRPV1 to TRPV4 as important tools for the treatment of pain. TRPV1, perhaps the most important signal integrator in sensory nociceptors, is well established as an intriguing novel target for the treatment of pain. TRPV1 antagonism represents one of several novel mechanistic approaches to pain relief en route to the next-generation analgesic, and preclinical data indicate that TRPV1 antagonists might also provide a useful therapeutic option for urinary incontinence, pancreatitis, cough, and migraine (Szallasi et al., 2006). Most antiinflammatory drugs under development target the propagation and transmission of signals to the spinal cord, whereas TRPV1 antagonists target the generation of the nociceptive stimulus.

In this review, we clearly illustrate that TRPV channels are sensitive to modulation by exogenous small molecules. However, our limited knowledge of their endogenous ligands make them still substantially "orphan" receptors. Furthermore, except for TRPV1, the pharmacology of these channels is sparse, and selective molecular tools (ligands, blockers, and sensitizers) are missing but urgently required. In addition, information on the regions and amino acids involved in TRPV function is still missing. Because members of the TRPV family are critical players in peripheral nociception, a better knowledge of the ligand binding region could be used to rationally design novel antinociceptive or anti-inflammatory agents, and crystallographic analysis could shed light on the structural determinants of TRPV functionality. Finally, as our knowledge on the physiology and regulation of vanilloid receptors increases, so does the clinical relevance of the pharmacological manipulation of these ion channels.

\section{Acknowledgments}

We thank Drs. T. Voets, G. Owsianik, and K. Talavera for helpful suggestions and criticisms.

\section{References}

Ahern GP (2003) Activation of TRPV1 by the satiety factor oleoylethanolamide. J Biol Chem 278:30429-30434.

Ahern GP, Wang X, and Miyares RL (2006) Polyamines are potent ligands for the capsaicin receptor TRPV1. J Biol Chem 281:8991-8995.

Alexander SP, Mathie A, and Peters JA (2006) Guide to receptors and channels, 2nd edition (2006 revision). Br J Pharmacol 147 (Suppl 3):S1-S180.

Almási R, Szoke E, Bölcskei K, Varga A, Riedl Z, Sándor Z, Szolcsányi J, and Petho $\mathrm{G}$ (2008) Actions of 3-methyl- $N$-oleoyldopamine, 4-methyl- $N$-oleoyldopamine and $\mathrm{N}$-oleoylethanolamide on the rat TRPV1 receptor in vitro and in vivo. Life Sci 82:644-651.

Amadesi S, Cottrell GS, Divino L, Chapman K, Grady EF, Bautista F, Karanjia R, Barajas-Lopez C, Vanner S, Vergnolle N, et al. (2006) Protease-activated receptor 2 sensitizes TRPV1 by protein kinase C\{varepsilon\}- and A-dependent mechanisms in rats and mice. $J$ Physiol 575:555-571.

Amadesi S, Nie J, Vergnolle N, Cottrell GS, Grady EF, Trevisani M, Manni C, Geppetti P, McRoberts JA, Ennes H, et al. (2004) Protease-activated receptor 2 sensitizes the capsaicin receptor transient receptor potential vanilloid receptor 1 to induce hyperalgesia. J Neurosci 24:4300-4312.

Anand U, Otto WR, Casula MA, Day NC, Davis JB, Bountra C, Birch R, and Anand $\mathrm{P}$ (2006) The effect of neurotrophic factors on morphology, TRPV1 expression and capsaicin responses of cultured human DRG sensory neurons. Neurosci Lett $\mathbf{3 9 9}$ $51-56$.

Appendino G (2007) Capsaicin and capsaicinoids, in Modern Alkaloids: Structure, Isolation, Synthesis and Biology (Taglialatela-Scafati EFaO ed) pp 75-112, John Wiley \& Sons, Weinheim, Germany.

Appendino G, Daddario N, Minassi A, Moriello AS, De Petrocellis L, and Di Marzo V (2005a) The taming of capsaicin. Reversal of the vanilloid activity of $\mathrm{N}$ acylvanillamines by aromatic iodination. $J$ Med Chem 48:4663-4669.

Appendino G, De Petrocellis L, Trevisani M, Minassi A, Daddario N, Moriello AS, Gazzieri D, Ligresti A, Campi B, Fontana G, et al. (2005b) Development of the firs ultra-potent "capsaicinoid" agonist at transient receptor potential vanilloid type 1 (TRPV1) channels and its therapeutic potential. $J$ Pharmacol Exp Ther 312:561570 .

Appendino G, Ech-Chahad A, Minassi A, Bacchiega S, De Petrocellis L, and Di Marzo V (2007) Structure-activity relationships of the ultrapotent vanilloid resiniferatoxin (RTX): the homovanillyl moiety. Bioorg Med Chem Lett 17:132-135.

Appendino G, Minassi A, Morello AS, De Petrocellis L, and Di Marzo V (2002 $N$-Acylvanillamides: development of an expeditious synthesis and discovery of new acyl templates for powerful activation of the vanilloid receptor. J Med Chem 45:3739-3745.

Appendino G, Minassi A, Pagani A, and Ech-Chahad A (2008) The role of natural products in the ligand deorphanization of TRP channels. Curr Pharm Des 14:2-17. Bang S, Kim KY, Yoo S, Lee SH, and Hwang SW (2007) Transient receptor potential V2 expressed in sensory neurons is activated by probenecid. Neurosci Lett 425: $120-125$

Baumann TK and Martenson ME (2000) Extracellular protons both increase the activity and reduce the conductance of capsaicin-gated channels. J Neurosci 20: RC80.

Bhave G, Hu HJ, Glauner KS, Zhu W, Wang H, Brasier DJ, Oxford GS, and Gereau RW 4th (2003) Protein kinase C phosphorylation sensitizes but does not activate the capsaicin receptor transient receptor potential vanilloid 1 (TRPV1). Proc Natl Acad Sci U S A 100:12480-12485.

Bhave G, Zhu W, Wang H, Brasier DJ, Oxford GS, and Gereau RW 4th (2002) cAMP-dependent protein kinase regulates desensitization of the capsaicin receptor (VR1) by direct phosphorylation. Neuron 35:721-731

Binshtok AM, Bean BP, and Woolf CJ (2007) Inhibition of nociceptors by TRPV1 mediated entry of impermeant sodium channel blockers. Nature 449:607-610.

Blum CA, Zheng X, Brielmann H, Hodgetts KJ, Bakthavatchalam R, Chandrasekhar J, Krause JE, Cortright D, Matson D, Crandall M, et al. (2008) Aminoquinazolines as TRPV1 antagonists: modulation of drug-like properties through the exploration of 2-position substitution. Bioorg Med Chem Lett 18:4573-4577.

Boels K, Glassmeier G, Herrmann D, Riedel IB, Hampe W, Kojima I, Schwarz JR, and Schaller HC (2001) The neuropeptide head activator induces activation and translocation of the growth-factor-regulated $\mathrm{Ca}^{2+}$-permeable channel GRC. J Cell Sci 114:3599-3606.

Bogeski I, Bozem M, Sternfeld L, Hofer HW, and Schulz I (2006) Inhibition of protein tyrosine phosphatase $1 \mathrm{~B}$ by reactive oxygen species leads to maintenance of $\mathrm{Ca}^{2+}$ influx following store depletion in HEK 293 cells. Cell Calcium 40:1-10.

Broad LM, Mogg AJ, Beattie RE, Ogden AM, Blanco MJ, and Bleakman D (2009) TRP channels as emerging targets for pain therapeutics. Expert Opin Ther Targets 13:69-81.

Brown BS, Keddy R, Zheng GZ, Schmidt RG, Koenig JR, McDonald HA, Bianchi BR, Honore P, Jarvis MF, Surowy CS, et al. (2008) Tetrahydropyridine-4-carboxamides as novel, potent transient receptor potential vanilloid 1 (TRPV1) antagonists. Bioorg Med Chem 16:8516-8525.

Caterina MJ, Leffler A, Malmberg AB, Martin WJ, Trafton J, Petersen-Zeitz KR, Koltzenburg M, Basbaum AI, and Julius D (2000) Impaired nociception and pain sensation in mice lacking the capsaicin receptor. Science 288:306-313.

Caterina MJ, Rosen TA, Tominaga M, Brake AJ, and Julius D (1999) A capsaicinreceptor homologue with a high threshold for noxious heat. Nature 398:436-441.

Caterina MJ, Schumacher MA, Tominaga M, Rosen TA, Levine JD, and Julius D (1997) The capsaicin receptor: a heat-activated ion channel in the pain pathway. Nature 389:816-824. 
Cha SK, Wu T, and Huang CL (2008) Protein kinase C inhibits caveolae-mediated endocytosis of TRPV5. Am J Physiol Renal Physiol 294:F1212-21.

Chang Q, Hoefs S, van der Kemp AW, Topala CN, Bindels RJ, and Hoenderop JG (2005) The beta-glucuronidase klotho hydrolyzes and activates the TRPV5 channel. Science 310:490-493.

Chou MZ, Mtui T, Gao YD, Kohler M, and Middleton RE (2004) Resiniferatoxin binds to the capsaicin receptor (TRPV1) near the extracellular side of the S4 transmembrane domain. Biochemistry 43:2501-2511.

Chung JU, Kim SY, Lim JO, Choi HK, Kang SU, Yoon HS, Ryu H, Kang DW, Lee J, Kang B, et al. (2007) Alpha-substituted $N$-(4-tert-butylbenzyl)-N'-[4-(methylsulfonylamino)benzyl]thiourea analogues as potent and stereospecific TRPV1 antagonists. Bioorg Med Chem 15:6043-6053.

Chung MK, Güler AD, and Caterina MJ (2005) Biphasic currents evoked by chemical or thermal activation of the heat-gated ion channel, TRPV3. J Biol Chem 280: $15928-15941$.

Chung MK, Lee H, Mizuno A, Suzuki M, and Caterina MJ (2004) 2-aminoethoxydiphenyl borate activates and sensitizes the heat-gated ion channel TRPV3. J Neurosci 24.5177-5182.

Cornett PM, Matta JA, and Ahern GP (2008) General anesthetics sensitize the capsaicin receptor TRPV1. Mol Pharmacol 74:1261-1268.

Cuypers E, Yanagihara A, Karlsson E, and Tytgat J (2006) Jellyfish and other cnidarian envenomations cause pain by affecting TRPV1 channels. FEBS Lett 580:5728-5732.

Dessaint J, Yu W, Krause JE, and Yue L (2004) Yohimbine inhibits firing activities of rat dorsal root ganglion neurons by blocking $\mathrm{Na}^{+}$channels and vanilloid VR1 receptors. Eur J Pharmacol 485:11-20.

Doherty EM, Fotsch C, Bo Y, Chakrabarti PP, Chen N, Gavva N, Han N, Kelly MG, Kincaid J, Klionsky L, et al. (2005) Discovery of potent, orally available vanilloid receptor-1 antagonists. Structure-activity relationship of $N$-aryl cinnamides. J Med Chem 48:71-90.

Ech-Chahad A, Bouyazza L, and Appendino G (2006) A convenient synthesis of 5 '-iodoresiniferatoxin (I-RTX). Nat Prod Commun 1:114-115.

Elitt CM, McIlwrath SL, Lawson JJ, Malin SA, Molliver DC, Cornuet PK, Koerber HR, Davis BM, and Albers KM (2006) Artemin overexpression in skin enhances expression of TRPV1 and TRPA1 in cutaneous sensory neurons and leads to behavioral sensitivity to heat and cold. J Neurosci 26:8578-8587.

Fernandes J, Lorenzo IM, Andrade YN, Garcia-Elias A, Serra SA, FernándezFernández JM, and Valverde MA (2008) IP3 sensitizes TRPV4 channel to the mechano- and osmotransducing messenger $5^{\prime}-6^{\prime}$-epoxyeicosatrienoic acid. $J$ Cell Biol 181:143-155.

García-Martinez C, Humet M, Planells-Cases R, Gomis A, Caprini M, Viana F, De La Pena E, Sanchez-Baeza F, Carbonell T, De Felipe C, et al. (2002) Attenuation of thermal nociception and hyperalgesia by VR1 blockers. Proc Natl Acad Sci U S A 99:2374-2379.

García-Martínez C, Morenilla-Palao C, Planells-Cases R, Merino JM, and FerrerMontiel A (2000) Identification of an aspartic residue in the P-loop of the vanilloid receptor that modulates pore properties. J Biol Chem 275:32552-32558.

Gavva NR, Bannon AW, Hovland DN Jr, Lehto SG, Klionsky L, Surapaneni S, Immke DC, Henley C, Arik L, Bak A, et al. (2007) Repeated administration of vanilloid receptor TRPV1 antagonists attenuates hyperthermia elicited by TRPV1 blockade. J Pharmacol Exp Ther 323:128-137.

Gavva NR, Tamir R, Klionsky L, Norman MH, Louis JC, Wild KD, and Treanor JJ (2005) Proton activation does not alter antagonist interaction with the capsaicinbinding pocket of TRPV1. Mol Pharmacol 68:1524-1533.

Gkika D, Topala CN, Chang Q, Picard N, Thébault S, Houillier P, Hoenderop JG, and Bindels RJ (2006) Tissue kallikrein stimulates $\mathrm{Ca}^{2+}$ reabsorption via PKCdependent plasma membrane accumulation of TRPV5. EMBO J 25:4707-4716.

Gore VK, Ma VV, Tamir R, Gavva NR, Treanor JJ, and Norman MH (2007) Structure-activity relationship (SAR) investigations of substituted imidazole analogs as TRPV1 antagonists. Bioorg Med Chem Lett 17:5825-5830.

Grant AD, Cottrell GS, Amadesi S, Trevisani M, Nicoletti P, Materazzi S, Altier C Cenac N, Zamponi GW, Bautista-Cruz F, et al. (2007) Protease-activated receptor 2 sensitizes the transient receptor potential vanilloid 4 ion channel to cause mechanical hyperalgesia. J Physiol 578:715-733.

Gullapalli S, Thomas A, Lingam PR, Kattige, V, Gudi GS, and Khairatkar-Joshi N (2008) GRC 15133-A novel, selective TRPV3 antagonist with anti-hyperalgesic effects in inflammatory and neuropathic pain. CHI-World Pharmaceutical Congress; 12-13 May 2008; Philadelphia. Available at: http://www.glenmarkpharma.com/research/pdf/GRC_15133_n_GRC17173_CHIs_Painconference_2008.pdf

Gunthorpe MJ, Rami HK, Jerman JC, Smart D, Gill CH, Soffin EM, Luis Hannan S, Lappin SC, Egerton J, Smith GD, et al. (2004) Identification and characterisation of SB-366791, a potent and selective vanilloid receptor (VR1/TRPV1) antagonist. Neuropharmacology 46:133-149.

Harrison N and Nau C (2008) Sensitization of nociceptive ion channels by inhaled anesthetics-a pain in the gas? Mol Pharmacol 74:1180-1182.

Himmel HM, Kiss T, Borvendeg SJ, Gillen C, and Illes P (2002) The arginine-rich hexapeptide R4W2 is a stereoselective antagonist at the vanilloid receptor 1: a $\mathrm{Ca}^{2+}$ imaging study in adult rat dorsal root ganglion neurons. J Pharmacol Exp Ther 301:981-986.

Hoenderop JG, Hartog A, Stuiver M, Doucet A, Willems PH, and Bindels RJ (2000) Localization of the epithelial $\mathrm{Ca}^{2+}$ channel in rabbit kidney and intestine. $J \mathrm{Am}$ Soc Nephrol 11:1171-1178.

Hoenderop JG, van der Kemp AW, Hartog A, van de Graaf SF, van Os CH, Willems $\mathrm{PH}$, and Bindels RJ (1999) Molecular identification of the apical $\mathrm{Ca}^{2+}$ channel in 1, 25- dihydroxyvitamin D3-responsive epithelia. J Biol Chem 274:8375-8378.

Hu H, Grandl J, Bandell M, Petrus M, and Patapoutian A (2009) Two amino acid residues determine 2-APB sensitivity of the ion channels TRPV3 and TRPV4. Proc Natl Acad Sci U S A 106:1626-1631.

Hu HZ, Xiao R, Wang C, Gao N, Colton CK, Wood JD, and Zhu MX (2006) Potenti ation of TRPV3 channel function by unsaturated fatty acids. J Cell Physiol 208: 201-212.

Huang SM, Bisogno T, Trevisani M, Al-Hayani A, De Petrocellis L, Fezza F, Tognetto M, Petros TJ, Krey JF, Chu CJ, et al. (2002) An endogenous capsaicin-like substance with high potency at recombinant and native vanilloid VR1 receptors. Proc Natl Acad Sci U S A 99:8400-8405.

Hwang SW, Cho H, Kwak J, Lee SY, Kang CJ, Jung J, Cho S, Min KH, Suh YG, Kim D, et al. (2000) Direct activation of capsaicin receptors by products of lipoxygenases: endogenous capsaicin-like substances. Proc Natl Acad Sci U S A 97:61556160 .

Ichikawa $\mathrm{H}$ and Sugimoto $\mathrm{T}$ (2000) Vanilloid receptor 1-like receptor-immunoreactive primary sensory neurons in the rat trigeminal nervous system. Neuroscience 101:719-725.

Iwata Y, Katanosaka Y, Arai Y, Komamura K, Miyatake K, and Shigekawa M (2003) A novel mechanism of myocyte degeneration involving the $\mathrm{Ca}^{2+}$-permeable growth factor-regulated channel. J Cell Biol 161:957-967.

Jiang Y, Ferguson WB, and Peng JB (2007) WNK4 enhances TRPV5-mediated calcium transport: potential role in hypercalciuria of familial hyperkalemic hypertension caused by gene mutation of WNK4. Am J Physiol Renal Physiol 292:F545F554.

Jin X, Morsy N, Winston J, Pasricha PJ, Garrett K, and Akbarali HI (2004) Modulation of TRPV1 by nonreceptor tyrosine kinase, c-Src kinase. Am J Physiol Cell Physiol 287:C558-C563.

Jordt SE and Julius D (2002) Molecular basis for species-specific sensitivity to "hot" chili peppers. Cell 108:421-430.

Jung J, Hwang SW, Kwak J, Lee SY, Kang CJ, Kim WB, Kim D, and Oh U (1999 Capsaicin binds to the intracellular domain of the capsaicin-activated ion channel $J$ Neurosci 19:529-538.

Jung J, Shin JS, Lee SY, Hwang SW, Koo J, Cho H, and Oh U (2004) Phosphorylation of vanilloid receptor 1 by $\mathrm{Ca}^{2+} /$ calmodulin-dependent kinase II regulates its vanilloid binding. J Biol Chem 279:7048-7054.

Juvin V, Penna A, Chemin J, Lin YL, and Rassendren FA (2007) Pharmacological characterization and molecular determinants of the activation of TRPV2 channel orthologs by 2-aminoethoxydiphenyl borate. Mol Pharmacol 72:1258-1268.

Kanzaki M, Zhang YQ, Mashima H, Li L, Shibata H, and Kojima I (1999) Translocation of a calcium-permeable cation channel induced by insulin-like growth factor-I. Nat Cell Biol 1:165-170.

Kitaguchi T and Swartz KJ (2005) An inhibitor of TRPV1 channels isolated from funnel web spider venom. Biochemistry 44:15544-15549.

Lambers TT, Oancea E, de Groot T, Topala CN, Hoenderop JG, and Bindels RJ (2007) Extracellular $\mathrm{pH}$ dynamically controls cell surface delivery of functiona TRPV5 channels. Mol Cell Biol 27:1486-1494

Lambers TT, Weidema AF, Nilius B, Hoenderop JG, and Bindels RJ (2004) Regula tion of the mouse epithelial $\mathrm{Ca}^{2+}$ channel TRPV 6 by the $\mathrm{Ca}^{2+}$-sensor calmodulin $J$ Biol Chem 279:28855-28861.

Lee J, Kang SU, Kil MJ, Shin M, Lim JO, Choi HK, Jin MK, Kim SY, Kim SE, Lee YS, et al. (2005) Analysis of structure-activity relationships for the 'A-region' of $N$-(4-t-butylbenzyl)- $N$ '-[4-(methylsulfonylamino)benzyl]thiourea analogues as TRPV1 antagonists. Bioorg Med Chem Lett 15:4136-4142.

Lee J, Lee J, Kang M, Shin M, Kim JM, Kang SU, Lim JO, Choi HK, Suh YG, Park $\mathrm{HG}$, et al. (2003) $N$-(3-acyloxy-2-benzylpropyl)- $N^{\prime}$-[4-(methylsulfonylamino)benzyl]thiourea analogues: novel potent and high affinity antagonists and partia antagonists of the vanilloid receptor. J Med Chem 46:3116-3126.

Leffler A, Fischer MJ, Rehner D, Kienel S, Kistner K, Sauer SK, Gavva NR, Reeh $\mathrm{PW}$, and Nau C (2008) The vanilloid receptor TRPV1 is activated and sensitized by local anesthetics in rodent sensory neurons. J Clin Invest 118:763-776.

Leffler A, Linte RM, Nau C, Reeh P, and Babes A (2007) A high-threshold heatactivated channel in cultured rat dorsal root ganglion neurons resembles TRPV 2 and is blocked by gadolinium. Eur $J$ Neurosci 26:12-22:12-22.

Lewinter RD, Skinner K, Julius D, and Basbaum AI (2004) Immunoreactive TRPV-2 (VRL-1), a capsaicin receptor homolog, in the spinal cord of the rat. J Comp Neurol 470:400-408.

Liedtke W, Choe Y, Martí-Renom MA, Bell AM, Denis CS, Sali A, Hudspeth AJ, Friedman JM, and Heller S (2000) Vanilloid receptor-related osmotically activated channel (VR-OAC), a candidate vertebrate osmoreceptor. Cell 103:525-535.

Liu L and Simon SA (1996) Similarities and differences in the currents activated by capsaicin, piperine, and zingerone in rat trigeminal ganglion cells. $J$ Neurophysio 76:1858-1869.

Lu P, Boros S, Chang Q, Bindels RJ, and Hoenderop JG (2008) The \{beta glucuronidase klotho exclusively activates the epithelial $\mathrm{Ca}^{2+}$ channels TRPV5 and TRPV6. Nephrol Dial Transplant 23:3397-3402.

Macpherson LJ, Hwang SW, Miyamoto T, Dubin AE, Patapoutian A, and Story GM (2006) More than cool: promiscuous relationships of menthol and other sensory compounds. Mol Cell Neurosci 32:335-343.

Maione S, De Petrocellis L, de Novellis V, Moriello AS, Petrosino S, Palazzo E, Ross FS, Woodward DF, and Di Marzo V (2007) Analgesic actions of $N$-arachidonoylserotonin, a fatty acid amide hydrolase inhibitor with antagonistic activity at vanilloid TRPV1 receptors. $\mathrm{Br}$ J Pharmacol 150:766-781.

Marincsák R, Tóth BI, Czifra G, Szabó T, Kovács L, and Bíró T (2008) The analgesic drug, tramadol, acts as an agonist of the transient receptor potential vanilloid-1. Anesth Analg 106:1890-1896.

Matta JA, Miyares RL, and Ahern GP (2007) TRPV1 is a novel target for omega-3 polyunsaturated fatty acids. J Physiol 578:397-411.

McDonald HA, Neelands TR, Kort M, Han P, Vos MH, Faltynek CR, Moreland RB, and Puttfarcken PS (2008) Characterization of A-425619 at native TRPV1 receptors: a comparison between dorsal root ganglia and trigeminal ganglia. Eur $J$ Pharmacol 596:62-69.

McNamara FN, Randall A, and Gunthorpe MJ (2005) Effects of piperine, the pungent component of black pepper, at the human vanilloid receptor (TRPV1). $\mathrm{Br} J$ Pharmacol 144:781-790. 
Mellor IR, Ogilvie J, Pluteanu F, Clothier RH, Parker TL, Rosini M, Minarini A, Tumiatti V, and Melchiorre C (2004) Methoctramine analogues inhibit responses to capsaicin and protons in rat dorsal root ganglion neurons. Eur J Pharmacol 505:37-50.

Messeguer A, Planells-Cases R, and Ferrer-Montiel A (2006) Physiology and pharmacology of the vanilloid receptor. Curr Neuropharmacol 4:1-15.

Meyers JR, MacDonald RB, Duggan A, Lenzi D, Standaert DG, Corwin JT, and Corey DP (2003) Lighting up the senses: FM1-43 loading of sensory cells through nonselective ion channels. J Neurosci 23:4054-4065.

Mohapatra DP, Wang SY, Wang GK, and Nau C (2003) A tyrosine residue in TM6 of the vanilloid receptor TRPV1 involved in desensitization and calcium permeability of capsaicin-activated currents. Mol Cell Neurosci 23:314-324.

Montell C (2005) The TRP superfamily of cation channels. Sci STKE 272:re3.

Moqrich A, Hwang SW, Earley TJ, Petrus MJ, Murray AN, Spencer KS, Andahazy M, Story GM, and Patapoutian A (2005) Impaired thermosensation in mice lacking TRPV3, a heat and camphor sensor in the skin. Science 307:1468-1472.

Moran MM, Wei DS, Zhen X, Mandel-Brehm J, Witek J, Yaksh T, McCumber D, Zhao M, Chong JA, Fanger CM, et al. (2007) Potent and selective antagonists validate TRPV3 as a target for analgesic therapeutics. Soc Neurosci Abstr 33: 143.5 .

Morenilla-Palao C, Planells-Cases R, García-Sanz N, and Ferrer-Montiel A (2004) Regulated exocytosis contributes to protein kinase C potentiation of vanilloid receptor activity. J Biol Chem 279:25665-25672.

Morita A, Iwasaki Y, Kobata K, Iida T, Higashi T, Oda K, Suzuki A, Narukawa M, Sasakuma S, Yokogoshi H, et al. (2006) Lipophilicity of capsaicinoids and capsinoids influences the multiple activation process of rat TRPV1. Life Sci 79:23032310 .

Moriyama T, Higashi T, Togashi K, Iida T, Segi E, Sugimoto Y, Tominaga T, Narumiya S, and Tominaga M (2005) Sensitization of TRPV1 by EP1 and IP reveals peripheral nociceptive mechanism of prostaglandins. Mol Pain 1:3.

Moriyama T, Iida T, Kobayashi K, Higashi T, Fukuoka T, Tsumura H, Leon C, Suzuki N, Inoue K, Gachet C, et al. (2003) Possible involvement of P2Y2 metabotropic receptors in ATP-induced transient receptor potential vanilloid receptor 1-mediated thermal hypersensitivity. J Neurosci 23:6058-6062.

Moussaieff A, Rimmerman N, Bregman T, Straiker A, Felder CC, Shoham S, Kashman Y, Huang SM, Lee H, Shohami E, et al. (2008) Incensole acetate, an incense component, elicits psychoactivity by activating TRPV3 channels in the brain. FASEB J 22:3024-3034.

Myrdal SE and Steyger PS (2005) TRPV1 regulators mediate gentamicin penetration of cultured kidney cells. Hear Res 204:170-182.

Nagasawa M, Nakagawa Y, Tanaka S, and Kojima I (2007) Chemotactic peptide fMetLeuPhe induces translocation of the TRPV2 channel in macrophages. J Cell Physiol 210:692-702.

Neeper MP, Liu Y, Hutchinson TL, Wang Y, Flores CM, and Qin N (2007) Activation properties of heterologously expressed mammalian TRPV2: evidence for species dependence. J Biol Chem 282:15894-15902.

Nilius B and Mahieu F (2006) A road map for TRP(I)PS. Mol Cell 22:297-307.

Nilius B, Owsianik G, and Voets T (2008) Transient receptor potential channels meet phosphoinositides. EMBO J 27:2809-2816.

Nilius B, Owsianik G, Voets T, and Peters JA (2007) Transient receptor potential channels in disease. Physiol Rev 87:165-217.

Nilius B, Prenen J, Vennekens R, Hoenderop JG, Bindels RJ, and Droogmans G (2001a) Pharmacological modulation of monovalent cation currents through the epithelial $\mathrm{Ca}^{2+}$ channel ECaC. Br J Pharmacol 134:453-462.

Nilius B, Prenen J, Wissenbach U, Bödding M, and Droogmans G (2001b) Differential activation of the volume-sensitive cation channel TRP12 (OTRPC4) and volume-regulated anion currents in HEK-293 cells. Pflugers Arch 443:227-233.

Nilius B and Voets T (2005) Trp channels: a TR(I)P through a world of multifunctional cation channels. Pflugers Arch 451:1-10.

Nilius B, Vriens J, Prenen J, Droogmans G, and Voets T (2004) TRPV4 calcium entry channel: a paradigm for gating diversity. Am J Physiol Cell Physiol 286:C195C205.

Nilius B, Watanabe H, and Vriens J (2003) The TRPV4 channel: structure-function relationship and promiscuous gating behaviour. Pflugers Arch 446:298-303.

Ohta T, Ikemi Y, Murakami M, Imagawa T, Otsuguro K, and Ito S (2006) Potentiation of transient receptor potential V1 functions by the activation of metabotropic 5-hydroxytryptamine receptors in rat primary sensory neurons. $J$ Physiol 576: $809-822$.

Ohta T, Imagawa T, and Ito S (2007) Novel agonistic action of mustard oil on recombinant and endogenous porcine transient receptor potential V1 (pTRPV1) channels. Biochem Pharmacol 73:1646-1656.

Oseguera AJ, Islas LD, García-Villegas R, and Rosenbaum T (2007) On the mechanism of TBA block of the TRPV1 channel. Biophys $J$ 92:3901-3914.

Owsianik G, D'hoedt D, Voets T, and Nilius B (2006) Structure-function relationship of the TRP channel superfamily. Rev Physiol Biochem Pharmacol 156:61-90.

Pareek TK, Keller J, Kesavapany S, Agarwal N, Kuner R, Pant HC, Iadarola MJ, Brady RO, and Kulkarni AB (2007) Cyclin-dependent kinase 5 modulates nociceptive signaling through direct phosphorylation of transient receptor potential vanilloid 1. Proc Natl Acad Sci US A 104:660-665.

Pareek TK, Keller J, Kesavapany S, Pant HC, Iadarola MJ, Brady RO, and Kulkarni $\mathrm{AB}$ (2006) Cyclin-dependent kinase 5 activity regulates pain signaling. Proc Natl Acad Sci U S A 103:791-796.

Pareek TK and Kulkarni AB (2006) Cdk5: a new player in pain signaling. Cell Cycle 5:585-588.

Patwardhan AM, Jeske NA, Price TJ, Gamper N, Akopian AN, and Hargreaves KM (2006) The cannabinoid WIN 55,212-2 inhibits transient receptor potential vanilloid 1 (TRPV1) and evokes peripheral antihyperalgesia via calcineurin. Proc Natl Acad Sci U S A 103:11393-11398.

Pedersen SF, Owsianik G, and Nilius B (2005) TRP channels: an overview. Cell Calcium 38:233-252.
Peier AM, Reeve AJ, Andersson DA, Moqrich A, Earley TJ, Hergarden AC, Story GM, Colley S, Hogenesch JB, McIntyre P, et al. (2002) A heat-sensitive TRP channel expressed in keratinocytes. Science 296:2046-2049.

Penna A, Juvin V, Chemin J, Compan V, Monet M, and Rassendren FA (2006) PI3-kinase promotes TRPV2 activity independently of channel translocation to the plasma membrane. Cell Calcium 39:495-507.

Pomonis JD, Harrison JE, Mark L, Bristol DR, Valenzano KJ, and Walker K (2003) $N$-(4-tertiarybutylphenyl)-4-(3-cholorphyridin-2-yl)tetrahydropyrazine-1 $(2 \mathrm{H})$ carbox-amide (BCTC), a novel, orally effective vanilloid receptor 1 antagonist with analgesic properties: II. in vivo characterization in rat models of inflammatory and neuropathic pain. J Pharmacol Exp Ther 306:387-393.

Puntambekar P, Van Buren J, Raisinghani M, Premkumar LS, and Ramkumar V (2004) Direct interaction of adenosine with the TRPV1 channel protein. J Neurosc 24:3663-3671.

Qin N, Neeper MP, Liu Y, Hutchinson TL, Lubin ML, and Flores CM (2008) TRPV2 is activated by cannabidiol and mediates CGRP release in cultured rat dorsal root ganglion neurons. J Neurosci 28:6231-6238.

Rami HK, Thompson M, Stemp G, Fell S, Jerman JC, Stevens AJ, Smart D, Sargent B, Sanderson D, Randall AD, et al. (2006) Discovery of SB-705498: a potent selective and orally bioavailable TRPV1 antagonist suitable for clinical development. Bioorg Med Chem Lett 16:3287-3291.

Rami HK, Thompson M, Wyman P, Jerman JC, Egerton J, Brough S, Stevens AJ, Randall AD, Smart D, Gunthorpe MJ, et al. (2004) Discovery of small molecule antagonists of TRPV1. Bioorg Med Chem Lett 14:3631-3634.

Ramsey IS, Delling M, and Clapham DE (2006) An introduction to TRP channels. Annu Rev Physiol 68:619-647.

Reen RK, Roesch SF, Kiefer F, Wiebel FJ, and Singh J (1996) Piperine impairs cytochrome P4501A1 activity by direct interaction with the enzyme and not by down regulation of CYP1A1 gene expression in the rat hepatoma $5 \mathrm{~L}$ cell line. Biochem Biophys Res Commun 218:562-569.

Roh EJ, Keller JM, Olah Z, Iadarola MJ, and Jacobson KA (2008) Structure-activity relationships of 1,4-dihydropyridines that act as enhancers of the vanilloid receptor 1 (TRPV1). Bioorg Med Chem 16:9349-9358.

Rosa A, Deiana M, Corona G, Atzeri A, Incani A, Appendino G, and Dessì MA (2005) Protective effect of capsinoid on lipid peroxidation in rat tissues induced by Fe-NTA. Free Radic Res 39:1155-1162.

Salazar H, Llorente I, Jara-Oseguera A, García-Villegas R, Munari M, Gordon SE Islas LD, and Rosenbaum T (2008) A single N-terminal cysteine in TRPV1 determines activation by pungent compounds from onion and garlic. Nat Neurosci 11:255-261.

Schoeber JP, Hoenderop JG, and Bindels RJ (2007) Concerted action of associated proteins in the regulation of TRPV5 and TRPV6. Biochem Soc Trans 35:115-119. Shimizu I, Iida T, Horiuchi N, and Caterina MJ (2005) 5-Iodoresiniferatoxin evokes hypothermia in mice and is a partial transient receptor potential vanilloid 1 agonist in vitro. J Pharmacol Exp Ther 314:1378-1385.

Siemens J, Zhou S, Piskorowski R, Nikai T, Lumpkin EA, Basbaum AI, King D, and Julius D (2006) Spider toxins activate the capsaicin receptor to produce inflammatory pain. Nature 444:208-212

Smith PL, Maloney KN, Pothen RG, Clardy J, and Clapham DE (2006) Bisandrographolide from Andrographis paniculata activates TRPV4 channels. J Biol Chem 281:29897-29904.

Srinivasan K (2007) Black pepper and its pungent principle-piperine: a review of diverse physiological effects. Crit Rev Food Sci Nutr 47:735-748.

Stein AT, Ufret-Vincenty CA, Hua L, Santana LF, and Gordon SE (2006) Phosphoinositide 3-kinase binds to TRPV1 and mediates NGF-stimulated TRPV1 trafficking to the plasma membrane. J Gen Physiol 128:509-522.

Sternfeld L, Krause E, Schmid A, Anderie I, Latas A, Al-Shaldi H, Köhl A, Evers K Hofer HW, and Schulz I (2005) Tyrosine phosphatase PTP1B interacts with TRPV6 in vivo and plays a role in TRPV6-mediated calcium influx in HEK293 cells. Cell Signal 17:951-960.

Stotz SC, Vriens J, Martyn D, Clardy J, and Clapham DE (2008) Citral sensing by TRANSient receptor potential channels in dorsal root ganglion neurons. PLoS ONE 3:e2082.

Strotmann R, Harteneck C, Nunnenmacher K, Schultz G, and Plant TD (2000) OTRPC4, a nonselective cation channel that confers sensitivity to extracellula osmolarity. Nature Cell Biology 2:695-702.

Sugiura T, Tominaga M, Katsuya H, and Mizumura K (2002) Bradykinin lowers the threshold temperature for heat activation of vanilloid receptor 1. J Neurophysiol 88:544-548

Suh YG, Lee YS, Min KH, Park OH, Kim JK, Seung HS, Seo SY, Lee BY, Nam YH, Lee KO, et al. (2005) Novel potent antagonists of transient receptor potential channel, vanilloid subfamily member 1: structure-activity relationship of $1,3-$ diarylalkyl thioureas possessing new vanilloid equivalents. J Med Chem 48:58235836 .

Suh YG and Oh U (2005) Activation and activators of TRPV1 and their pharmaceutical implication. Curr Pharm Des 11:2687-2698.

Surowy CS, Neelands TR, Bianchi BR, McGaraughty S, El Kouhen R, Han P, Chu KL, McDonald HA, Vos M, Niforatos W, et al. (2008) ABT-102 ((R)-(5-tert-butyl2,3-dihydro-1H-inden-1-yl)-3-(1H-indazol-4-yl)-urea) blocks polymodal activation of TRPV1 receptors in vitro and heat-evoked firing of spinal dorsal horn neurons in vivo. J Pharmacol Exp Ther 326:879-888.

Surprenant A (2007) A pain TRP-ed up by PARs. J Physiol 578:631.

Susankova K, Tousova K, Vyklicky L, Teisinger J, and Vlachova V (2006) Reducing and oxidizing agents sensitize heat-activated vanilloid receptor (TRPV1) current. Mol Pharmacol 70:383-394.

Szallasi A and Blumberg PM (1989) Resiniferatoxin, a phorbol-related diterpene, acts as an ultrapotent analog of capsaicin, the irritant constituent in red pepper. Neuroscience 30:515-520.

Szallasi A, Cortright DN, Blum CA, and Eid SR (2007) The vanilloid receptor TRPV1 
10 years from channel cloning to antagonist proof-of-concept. Nat Rev Drug Discov 6:357-372.

Szallasi A, Cruz F, and Geppetti P (2006) TRPV1: a therapeutic target for novel analgesic drugs? Trends Mol Med 12:545-554.

Szallasi A and Di Marzo V (2000) New perspectives on enigmatic vanilloid receptors. Trends Neurosci 23:491-497.

Szallasi A, Szolcsanyi J, Szallasi Z, and Blumberg PM (1991) Inhibition of [3H]resiniferatoxin binding to rat dorsal root ganglion membranes as a novel approach in evaluating compounds with capsaicin-like activity. Naunyn Schmiedebergs Arch Pharmacol 344:551-556.

Thorneloe KS, Sulpizio AC, Lin Z, Figueroa DJ, Clouse AK, McCafferty GP, Chendrimada TP, Lashinger ES, Gordon E, Evans L, et al. (2008) GSK1016790A, a novel and potent TRPV4 channel agonist induces urinary bladder contraction and hyperactivity: part I. J Pharmacol Exp Ther 326:432-442.

Thyagarajan B, Benn BS, Christakos S, and Rohacs T (2009) Phospholipase Cmediated regulation of transient receptor potential vanilloid 6 channels: implications in active intestinal $\mathrm{Ca}^{2+}$ transport. Mol Pharmacol 75:608-616.

Tominaga M, Caterina MJ, Malmberg AB, Rosen TA, Gilbert H, Skinner K, Raumann BE, Basbaum AI, and Julius D (1998) The cloned capsaicin receptor integrates multiple pain-producing stimuli. Neuron 21:531-543.

Tominaga M, Wada M, and Masu M (2001) Potentiation of capsaicin receptor activity by metabotropic ATP receptors as a possible mechanism for ATP-evoked pain and hyperalgesia. Proc Natl Acad Sci US A 98:6951-6956.

Tóth A, Kedei N, Szabó T, Wang Y, and Blumberg PM (2002) Thapsigargin binds to and inhibits the cloned vanilloid receptor-1. Biochem Biophys Res Commun 293: $777-782$.

Tousova K, Vyklicky L, Susankova K, Benedikt J, and Vlachova V (2005) Gadolinium activates and sensitizes the vanilloid receptor TRPV1 through the external protonation sites. Mol Cell Neurosci 30:207-217.

Van Buren JJ, Bhat S, Rotello R, Pauza ME, and Premkumar LS (2005) Sensitization and translocation of TRPV1 by insulin and IGF-I. Mol Pain 1:17.

van de Graaf SF, Hoenderop JG, and Bindels RJ (2006) Regulation of TRPV5 and TRPV6 by associated proteins. Am J Physiol Renal Physiol 290:F1295-F1302.

Van Der Stelt M and Di Marzo V (2004) Endovanilloids. Putative endogenous ligands of transient receptor potential vanilloid 1 channels. Eur J Biochem 271:18271834.

Vennekens R, Owsianik G, and Nilius B (2008) Vanilloid transient receptor potential cation channels: an overview. Curr Pharm Des 14:18-31.

Voets T, Janssens A, Prenen J, Droogmans G, and Nilius B (2003) $\mathrm{Mg}^{2+}$-dependent gating and strong inward rectification of the cation channel TRPV6. J Gen Physiol 121:245-260.

Voets T, Prenen J, Fleig A, Vennekens R, Watanabe H, Hoenderop JG, Bindels RJ, Droogmans G, Penner R, and Nilius B (2001) CaT1 and the calcium releaseactivated calcium channel manifest distinct pore properties. J Biol Chem 276: 47767-47770.

Voets T, Talavera K, Owsianik G, and Nilius B (2005) Sensing with TRP channels. Nat Chem Biol 1:85-92.

Vogt-Eisele AK, Weber K, Sherkheli MA, Vielhaber G, Panten J, Gisselmann G, and Hatt H (2007) Monoterpenoid agonists of TRPV3. Br J Pharmacol 151:530-540.

Vriens J, Nilius B, and Vennekens R (2008) Herbal compounds and toxins modulating TRP channels. Curr Neuropharmacol 6:79-96.

Vriens J, Owsianik G, Fisslthaler B, Suzuki M, Janssens A, Voets T, Morisseau C, Hammock BD, Fleming I, Busse R, et al. (2005) Modulation of the $\mathrm{Ca}^{2+}$ permeable cation channel TRPV4 by cytochrome P450 epoxygenases in vascular endothelium. Circ Res 97:908-915.

Vriens J, Owsianik G, Janssens A, Voets T, and Nilius B (2007) Determinants of 4alpha -phorbol sensitivity in transmembrane domains 3 and 4 of the cation channel TRPV4. J Biol Chem 282:12796-12803.

Vriens J, Owsianik G, Voets T, Droogmans G, and Nilius B (2004a) Invertebrate TRP proteins as functional models for mammalian channels. Pflugers Arch 449:213226.

Vriens J, Watanabe H, Janssens A, Droogmans G, Voets T, and Nilius B (2004b) Cell swelling, heat, and chemical agonists use distinct pathways for the activation of the cation channel TRPV4. Proc Natl Acad Sci US A 101:396-401.
Wahl P, Foged C, Tullin S, and Thomsen C (2001) Iodo-resiniferatoxin, a new potent vanilloid receptor antagonist. Mol Pharmacol 59:9-15.

Walker KM, Urban L, Medhurst SJ, Patel S, Panesar M, Fox AJ, and McIntyre P (2003) The VR1 antagonist capsazepine reverses mechanical hyperalgesia in models of inflammatory and neuropathic pain. J Pharmacol Exp Ther 304:56-62.

Wang X, Miyares RL, and Ahern GP (2005) Oleoylethanolamide excites vagal sensory neurons, induces visceral pain and reduces short-term food intake in mice via TRPV1. J Physiol 564:541-547.

Wang Y, Szabo T, Welter JD, Toth A, Tran R, Lee J, Kang SU, Suh YG, Blumberg PM, and Lee J (2002) High affinity antagonists of the vanilloid receptor. Mol Pharmacol 62:947-956.

Watanabe H, Davis JB, Smart D, Jerman JC, Smith GD, Hayes P, Vriens J, Cairn W, Wissenbach U, Prenen J, et al. (2002) Activation of TRPV4 channels (hVRL2/mTRP12) by phorbol derivatives. $J$ Biol Chem 277:13569-13577.

Watanabe H, Vriens J, Prenen J, Droogmans G, Voets T, and Nilius B (2003) Anandamide and arachidonic acid use epoxyeicosatrienoic acids to activate TRPV4 channels. Nature 424:434-438.

Westaway SM, Brown SL, Conway E, Heightman TD, Johnson CN, Lapsley K, Macdonald GJ, MacPherson DT, Mitchell DJ, Myatt JW, et al. (2008a) The discovery of biaryl carboxamides as novel small molecule agonists of the motilin receptor. Bioorg Med Chem Lett 18:6429-6436.

Westaway SM, Chung YK, Davis JB, Holland V, Jerman JC, Medhurst SJ, Rami HK, Stemp G, Stevens AJ, Thompson M, et al. (2006) N-TETRAHYDROQUINOLINYL, $N$-quinolinyl and $N$-isoquinolinyl biaryl carboxamides as antagonists of TRPV1. Bioorg Med Chem Lett 16:4533-4536.

Westaway SM, Thompson M, Rami HK, Stemp G, Trouw LS, Mitchell DJ, Seal JT, Medhurst SJ, Lappin SC, Biggs J, et al. (2008b) Design and synthesis of 6-phenylnicotinamide derivatives as antagonists of TRPV1. Bioorg Med Chem Let 18:5609-5613.

Willette RN, Bao W, Nerurkar S, Yue TL, Doe CP, Stankus G, Turner GH, Ju H Thomas H, Fishman CE, et al. (2008) Systemic activation of the transient receptor potential V4 channel causes endothelial failure and circulatory collapse: Part 2. $J$ Pharmacol Exp Ther 326:443-452.

Wissenbach U, Bödding M, Freichel M, and Flockerzi V (2000) Trp12, a novel Trp related protein from kidney. FEBS Lett 485:127-134.

Wu C, Gavva NR, and Brennan TJ (2008) Effect of AMG0347, a transient receptor potential type V1 receptor antagonist, and morphine on pain behavior after plantar incision. Anesthesiology 108:1100-1108.

$\mathrm{Xu} \mathrm{H}$, Blair NT, and Clapham DE (2005) Camphor activates and strongly desensitizes the transient receptor potential vanilloid subtype 1 channel in a vanilloidindependent mechanism. $J$ Neurosci 25:8924-8937.

$\mathrm{Xu}$ H, Delling M, Jun JC, and Clapham DE (2006) Oregano, thyme and clove-derived flavors and skin sensitizers activate specific TRP channels. Nat Neurosci 9:628 635.

Xu H, Ramsey IS, Kotecha SA, Moran MM, Chong JA, Lawson D, Ge P, Lilly J, Silos-Santiago I, Xie Y, et al. (2002) TRPV3 is a calcium-permeable temperaturesensitive cation channel. Nature 418:181-186.

Yamauchi D, Raveendran NN, Pondugula SR, Kampalli SB, Sanneman JD, Harbidge DG, and Marcus DC (2005) Vitamin D upregulates expression of ECaC1 mRNA in semicircular canal. Biochem Biophys Res Commun 331:1353-1357.

Yang BH, Piao ZG, Kim YB, Lee CH, Lee JK, Park K, Kim JS, and Oh SB (2003) Activation of vanilloid receptor 1 (VR1) by eugenol. J Dent Res 82:781-785.

Yeh BI, Yoon J, and Huang CL (2006) On the role of pore helix in regulation of TRPV5 by extracellular protons. J Membr Biol 212:191-198.

Zhang X and McNaughton PA (2006) Why pain gets worse: the mechanism of hea hyperalgesia. J Gen Physiol 128:491-493.

Address correspondence to: Dr. Bernd Nilius, Department Mol Cell Biology, Laboratory of Ion Channel Research, KU Leuven, Campus Gasthuisberg, Herestraat 49, bus 802, B-3000 Leuven, Belgium. E-mail: bernd.nilius@ med.kuleuven.be 